\title{
Data Requirements for the Ferrocyanide Safety Issue Developed through the Data Quality Objectives Process
}

\author{
J. E. Meacham \\ R. J. Cash \\ G. T. Dukelow \\ H. Babad \\ Westinghouse Hanford Company \\ J. W. Buck \\ C. M. Anderson \\ B. A. Pulsipher \\ J. J. Toth \\ P. J. Turner \\ Pacific Northwest Laboratory
}

Date Published

August 1994

Prepared for the U.S. Department of Energy Office of Environmental Restoration and Waste Management

(W) Westinghouse $\begin{aligned} & \text { P.O. Box } 1970 \\ & \text { Hanford Company }\end{aligned}$

Hanford Operations and Engineering Contractor for the

U.S. Department of Energy under Contract DE-AC06-87RL10930

Approved for Public Release

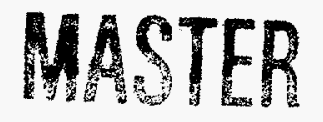









\section{DISCLAIMER}

Portions of this document may be illegible in electronic image products. Images are produced from the best available original document. 


\section{Key Words}

Ferrocyanide, DQO, data quality objectives, criteria, energetics, uncertainty, RSD, relative standard deviation, number of core samples, discomfort curve, confidence interval

\section{thos $8 / 11 / 94$ APPROVED FOR \\ 7. Abstract PUBLIC RELEASE}

4. Rev No.

3. Number

WHC-SD-WM-DQO-007

This document records the data quality objectives (DQO) process applied to the Ferrocyanide Safety Issue at the Hanford Site. Specifically, the major recommendations and findings from this Ferrocyanide DQO process are presented. The decision logic diagrams and decision error tolerances also are provided. The document includes the DQO sample-size formulas for determining specific tank sampling requirements.

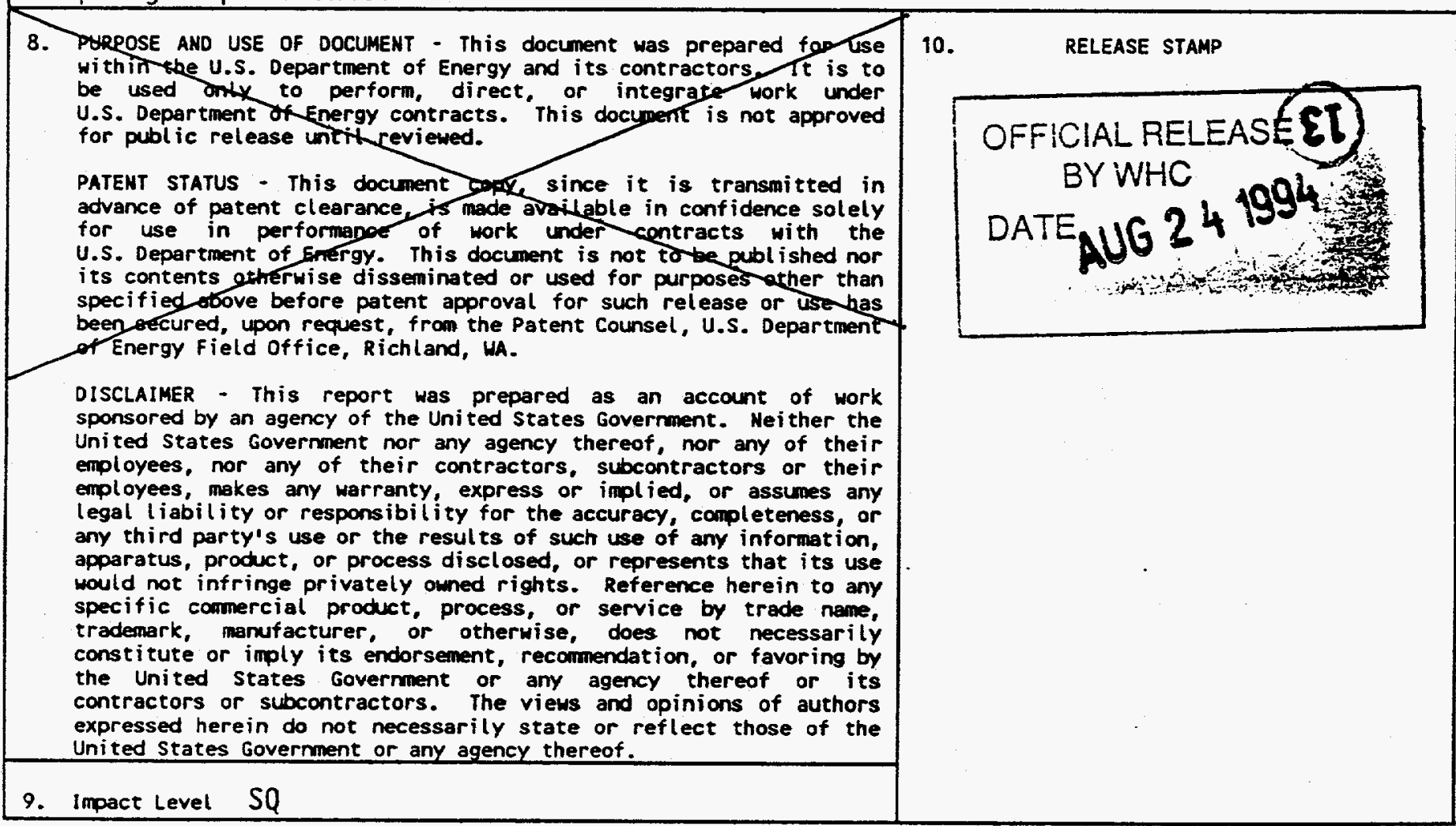


DATA REQUIREMENTS FOR THE FERROCYANIDE SAFETY ISSUE

DEVELOPED THROUGH THE DATA QUALITY OBJECTIVES PROCESS

\section{EXECUTIVE SUMMARY}

This document records the data quality objectives (DQO) process applied to the Ferrocyanide Safety Issue at the Hanford Site. Specifically, the major recommendations and findings from this Ferrocyanide DQO process are presented. The decision logic diagrams and decision error tolerances also are provided. The document. includes the DQO sample-size formulas for determining specific tank sampling requirements, and many of the justifications for decision thresholds and decision error tolerances are briefly described. More detailed descriptions are presented in other Ferrocyanide Safety Program companion documents referenced in this report. This is a living document, and the assumptions contained within will be refined as more data from sampling and characterization become available.

\section{FERROCYANIDE DQO PROCESS}

This particular application of the DQO process uses historical, monitoring, simulant, modeling, and sampling information to determine data requirements for characterizing tank waste containing ferrocyanide compounds ${ }^{1}$. The recommendations and decision logic presented in this report shall be used to develop tank-specific characterization plans for all Ferrocyanide Watch List tanks. These tank-specific characterization plans will specify the data requirements for the final data packages developed by the analytical 1aboratories. The information from these data packages can then be used to determine the safety category of each Ferrocyanide Watch List tank and to derive the appropriate measures needed to ensure continued safe interim storage. Tanks that are not on the Ferrocyanide Watch List are addressed through the safety screening module DQO (Babad and Redus 1994) or another DQO process. The safety screening module provides appropriate linkage between the ferrocyanide data requirements and the other safety data requirements.

Three important outputs of this particular DQO application are: (1) key decision rules for determining the safety category of Ferrocyanide Watch List tanks; (2) recommendations for the number of tank cores or samples to be taken; and (3) analytical requirements that feed into the tank-specific characterization plans.

1 The term ferrocyanide is used throughout this report to represent all ferrocyanide compounds; e.g., $\mathrm{Na}_{2} \mathrm{NiFe}(\mathrm{CN})_{6}$ and $\mathrm{NaCsNiFe}(\mathrm{CN})_{6}$. 


\section{PRIMARY DECISION RULES}

Based on previously established safety criteria (Postma et al. 1994), two key decision rules were identified to place ferrocyanide tanks into one of three categories (safe, conditionally safe, and unsafe). These decision rules were defined as follows:

- If the fuel concentration average for all homogenized quarter segment sludge layers (half segment for saltcake) is less than or equal to 8 wt\% as disodium nickel ferrocyanide $\left[\mathrm{Na}_{2} \mathrm{NiFe}(\mathrm{CN})_{6}\right]$ on an energy equivalent basis (i.e., $115 \mathrm{cal} / \mathrm{g}$ of dry material), then the tank is categorized as safe.

- If the fuel concentration average in any homogenized quarter segment sludge layer (half segment for saltcake) is greater than $8 w t \%$ and if the wt\% free water ${ }^{2}$ is greater than $4 / 3$ (wt\% fuel ${ }^{3}-8 w t \%$ ), then the tank is categorized as conditionally safe. Tanks with greater than 8 wt\% fuel that have less than the specified free water are categorized as unsafe.

Tanks categorized as safe or conditionally safe cannot support a propagating reaction. The temperature of the waste is a secondary data requirement that is used in support of the decision whether a tank is categorized as conditionally safe or unsafe. Temperature is not a core sample data value but is obtained from instrument tree measurements.

\section{RECOMMENDED NUMBER OF CORE SAMPLES}

The primary considerations for defining sampling requirements are the desired levels of protection from making incorrect decisions, and the expected spatial, sampling, and analytical variations. Judgements were made on the desired levels of protection against making decision errors and are discussed in Section 5.0 of this report. The following decision error tolerances were specified: less than a $20 \%$ chance of categorizing a tank with a true fue 1 concentration of $4 \mathrm{wt} \%$ as conditionally safe or unsafe; less than a $20 \%$ chance of categorizing a tank with a true fuel concentration of 8 wt\% as safe; less than a $5 \%$ chance of categorizing a tank with a true fuel concentration of 12 wt\% as safe, and less than a $1 \%$ chance of categorizing a tank with a true fuel concentration of 15 wt\% as safe. Similarly, decision error tolerances were also specified for the moisture decision rule to differentiate between conditionally safe and unsafe.

Estimates of the expected spatial, sampling, and analytical variations were derived from available core sample data for two tanks on the Ferrocyanide Watch List (tanks 241-C-109 and 241-C-112). Based on the specified error tolerances and assuming the variability estimated from the two sampled tanks

2 Free water is defined as the water removed from a sample by drying at $120{ }^{\circ} \mathrm{C}$ for 18 hours.

3 wt\% fuel represents the energy value of the sample based on an equivalent wt\% $\mathrm{Na}_{2} \mathrm{NiFe}(\mathrm{CN})_{6}$. Fuel content is calculated by measuring the exothermic energy of the sample and dividing by the reaction energy of $\mathrm{Na}_{2} \mathrm{NiFe}(\mathrm{CN})_{6}$ (Postma et al. 1994). 
are representative, two cores are sufficient to categorize a ferrocyanide tank as safe, conditionally safe, or unsafe. However, the estimate of variability will be updated as more data become available, which may increase the number of core samples required. Where possible, sampling locations should be chosen to increase the likelihood of obtaining samples that represent the true spatial variations within a tank (e.g., opposite sides or side-center for two cores, side-center-side for three cores).

\section{ANALYTICAL REQUIREMENTS}

\section{Primary Data Requirements}

Table S-1 provides a summary of the primary data requirements for Ferrocyanide Watch List tanks. Primary data are required from the 1 ab within 45 days of receipt of the last sample (e.g., if two cores are taken, after receipt of the second core). These analyses must be applied to quarter segments for sludge layers and half segments for saltcake layers (see Section 3.2 .1 for rationale). The quarter segment requirement for sludge layers will be reviewed after sampling and analyses of three to five ferrocyanide tanks. If aging (degradation) of the ferrocyanide is confirmed by analyses of these tanks, then the quarter segment analytical requirement may be relaxed to half or full segments.

Table S-1. Primary Data Requirements for Ferrocyanide Tanks.

\begin{tabular}{|c|c|c|c|c|}
\hline Analyte & Analytical Method' & Sample ${ }^{2}$ & $\begin{array}{l}\text { Decision } \\
\text { Threshold }\end{array}$ & $\begin{array}{c}\text { Required } \\
\text { Analytical } \\
\text { Uncertainty }\end{array}$ \\
\hline Total Fuel ${ }^{3}$ & $\begin{array}{l}\text { Differential Scanning } \\
\text { Calorimetry/Adiabatic } \\
\text { Calorimetry }\end{array}$ & $\frac{1}{4}$-Segment & $\begin{array}{c}8 \mathrm{wt} \% \\
(0.48 \mathrm{MJ} / \mathrm{kg} \text { or } \\
115 \mathrm{cal} / \mathrm{g})\end{array}$ & $\leq 10 \%^{4}$ \\
\hline Moisture Content & $\begin{array}{l}\text { Thermogravimetric } \\
\text { Analysis }\end{array}$ & $\frac{3}{4}$-Segment & $4 / 3$ (Fue $1-8$ ) & $\leq 10 \%^{5}$ \\
\hline
\end{tabular}

1 Other techniques that meet the required uncertainty also are acceptable.

2 Analyses are conducted on homogenized quarter segments for sludge and homogenized half segments for saltcake.

3 Calculated on a $\mathrm{Na}_{2} \mathrm{NiFe}(\mathrm{CN})_{6}$ energy equivalent basis.

4 Fuel values less than 2 wt\% $\mathrm{Na}_{2} \mathrm{NiFe}(\mathrm{CN})_{6}(28 \mathrm{cal} / \mathrm{g})$ on a dry basis do not require the specified analytical uncertainty.

5 Values less than 5 or greater than 35 wt\% water do not require the specified uncertainty.

Data on fuel and moisture concentration are required to categorize a ferrocyanide tank as safe, conditionally safe, or unsafe. Categorization of all the ferrocyanide tanks is necessary to resolve the Ferrocyanide Safety Issue. 
WHC-SD-WM-DQ0-007 Rev. 0

\section{Secondary Data Requirements}

Table S-2 provides a summary of the secondary data requirements for Ferrocyanide Watch List tanks. The secondary data requirements are not directly involved in the decision rule, but will expedite final resolution of the Ferrocyanide Safety Issue. These analyses are required with in 216 days of receipt of the last sample. The half segment (quarter segment for nickel) sample requirements for sludge and saltcake will be reviewed based on analyses of three to five ferrocyanide tanks. If aging is confirmed by analyses of these tanks, then the half segment analytical requirement may be relaxed to full segments.

Table S-2. Secondary Data Requirements for Ferrocyanide Tanks.

\begin{tabular}{|c|c|c|c|c|}
\hline Analyte & Analytical Method ${ }^{1}$ & Sample $e^{2}$ & $\begin{array}{c}\text { Required } \\
\text { Sensitivity }\end{array}$ & $\begin{array}{c}\text { Required } \\
\text { Analytical } \\
\text { Uncertainty }\end{array}$ \\
\hline Tank Temperature & Thermocouple & $N / A^{5}$ & $90^{\circ} \mathrm{C}$ & $\leq 10 \%$ \\
\hline Nickel & $\begin{array}{l}\text { Inductively Coupled } \\
\text { Plasmab }\end{array}$ & $\begin{array}{c}{ }^{\frac{3}{4}-\text { Segment }} \\
\text { (Siudge Only) }\end{array}$ & $500 \mu \mathrm{g} / \mathrm{g}$ & $\leq 10 \%$ \\
\hline Total Cyanide & Direct Analyses & $\begin{array}{l}\frac{1}{2}-\text { Segment } \\
\text { \& Liquid }\end{array}$ & 0.5 wt\% & $\leq 10 \%$ \\
\hline $\begin{array}{l}\text { Total Organic } \\
\text { Carbon }\end{array}$ & Furnace Oxidation & $\frac{1}{2}$-Segment & $1.0 \mathrm{wt} \%$ & $\leq 10 \%$ \\
\hline Cesium-137 & $\begin{array}{l}\text { Gamma Energy } \\
\text { Analys is }\end{array}$ & $\begin{array}{l}\text { 3-Segment } \\
\text { \& Liquid }\end{array}$ & $50 \mu \mathrm{Ci} / \mathrm{g}$ & $\leq 10 \%$ \\
\hline Strontium-90 & Beta Radiochemistry & $\begin{array}{l}\text { 3-Segment } \\
\text { \& Liquid }\end{array}$ & $50 \mu \mathrm{Ci} / \mathrm{g}$ & $\leq 10 \%$ \\
\hline
\end{tabular}

1 Other techniques that meet the required uncertainty also are acceptable.

2 All analyses are conducted on homogenized samples.

3 All required sensitivities are reported on a dry basis for solid samples.

4 Values less than the required sensitivity do not require the specified analytical uncertainty.

$5 \mathrm{~N} / \mathrm{A}=$ not applicable

6 Non-nickel crucibles must be used to reduce the potential for analytical bias.

Temperature of the waste is an important data requirement that is used in support of the decision whether a tank is conditionally safe or unsafe. If the fuel concentration is greater than $8 \mathrm{wt} \%$ and the moisture content is greater than $4 / 3$ (wt\% fuel - 8 wt\%), but the waste temperature is greater than $90^{\circ} \mathrm{C}$, then the tank is categorized as unsafe. This is because rapid moisture loss can not be ruled out for waste temperatures greater than $90{ }^{\circ} \mathrm{C}$.

Nickel is a signature analyte of the nickel ferrocyanide scavenging process (the only source of added nickel). Nickel analyses are conducted on homogenized quarter segments for sludge and are not performed on saltcake. 
Nickel offers analytical evidence that ferrocyanide once existed in the tank. This is important for resolving the Ferrocyanide Safety Issue because it verifies that the correct tanks were identified, and corroborates that aging has occurred. Confirmation of aging is necessary before the quarter/half segment analytical requirement can be relaxed to half/full segments.

Total cyanide and total organic carbon analyses provide information on fuel characterization. These analyses are conducted on homogenized half segments for sludge and saltcake. Without these measurements, it would be difficult to confirm whether a tank belongs on the Ferrocyanide or Organic Watch List (possibly both). This is important because these tanks are governed by slightly different sets of safety criteria (Postma et al. 1994, Babad and Turner 1993) and may require different monitoring and control procedures. Total cyanide and total organic carbon analyses also offer corroborative evidence of the total fuel content of the waste.

Strontium-90 and cesium-137 are the major heat-producing radionuclides in the ferrocyanide tanks. These analyses are conducted on homogenized half segments for sludge and saltcake. Strontium-90 and cesium-137 analyses offer confirmation of heat load and hot spot models developed for the Ferrocyanide Safety Program. Hot spot and heat load models are important in establishing the probability of a tank moving from the conditionally safe category to the unsafe category because of water evaporation.

\section{Tertiary Data Requirements}

Table S-3 provides a summary of the tertiary data requirements for Ferrocyanide Watch List tanks. These analyses are required within 216 days of receipt of the last sample. Analyses for consolidation and particle size will be reviewed based on results from three ferrocyanide tanks. If it is confirmed that the particle size is small (less than $2 \mu \mathrm{m}$ ) and that the waste retains considerable water after centrifuging, then these two analyses will be dropped for future ferrocyanide tanks.

All tertiary analyses are conducted only on sludge, and not on saltcake. Consolidation measurements are performed on a full segment basis, before homogenization. The remaining tertiary analyses are performed on a core composite basis. For example, if two core samples were taken from a tank, a sludge composite would be made for each core and the tertiary analyses (excluding consolidation) would be performed twice. Some of the tertiary analyses are performed on the drainable liquid from the cores. The drainable liquid from each core segment should be combined to form a single liquid composite for the core, similar to the process for the sludge composites.

Tertiary data are required for a variety of purposes in the Ferrocyanide Safety Program. Rheological and physical measurements are required to validate waste dryout (moisture retention and hot spot) models, and to evaluate aging models. Waste dryout models are important in establishing the probability of a tank moving from the conditionally safe to the unsafe category because of water evaporation. Validation of waste aging models provides an important linkage between the fuel value originally placed in the ferrocyanide tanks and the current analyses. Radiological and chemical analyses are necessary to validate waste aging models and to confirm waste 
transfer histories. It is important to confirm waste transfer histories because histories were used to identify which tanks belonged on the Ferrocyanide Watch List.

\section{CONCLUSIONS}

Two key decision rules were developed for placing ferrocyanide tanks into one of three safety categories, safe, conditionally safe, and unsafe. The type, quantity, and quality of data necessary to categorize the tanks and to resolve the Ferrocyanide Safety Issue were delineated. Assumptions used will be further validated and refined as characterization data become available. 
Table S-3. Tertiary Data Requirements for Ferrocyanide Tanks.

\begin{tabular}{|c|c|c|c|c|}
\hline Analyte & Analytical Method' & Sample $e^{2}$ & $\begin{array}{c}\text { Required } \\
\text { Sensitivity }\end{array}$ & $\begin{array}{c}\text { Required } \\
\text { Analytical } \\
\text { Uncertainty }\end{array}$ \\
\hline $\begin{array}{l}\text { Aluminum, Calcium, Iron, } \\
\text { Phosphorus, Sodium }\end{array}$ & $\begin{array}{l}\text { Inductively Coupled } \\
\text { Plasma }\end{array}$ & $\begin{array}{l}\text { Sludge Composite } \\
\text { Drainable Liquid }\end{array}$ & $500 \mu g / g$ & $\leq 25 \%$ \\
\hline $\begin{array}{l}\text { Chloride, Fluoride, Witrate, } \\
\text { Nitrite, Phosphate }\end{array}$ & Ion Chromatography & $\begin{array}{l}\text { Sludge Composite } \\
\text { Drainable Liquid }\end{array}$ & $500 \mu \mathrm{g} / \mathrm{g}$ & $\leq 25 x$ \\
\hline pH & Ion Selective Electrode & Drainable Liquid & $4-12$ & $\pm 0.5^{5}$ \\
\hline Total Carbon & Coul ometric Detection & sludge Composite & $1,200 \mu \mathrm{g} / \mathrm{g}$ & $\leq 25 \%$ \\
\hline Total Inorganic Carbon & Coulometric Detection & sludge Composite & $1,200 \mu \mathrm{g} / \mathrm{g}$ & $\leq 25 x$ \\
\hline Total Alpha & Proportional Counting & Sludge Composite & $2 \mu \mathrm{Ci} / \mathrm{g}$ & $\leq 18 \%$ \\
\hline Total Beta & Proportional Counting & Sludge Composite & $50 \mu \mathrm{Ci} / \mathrm{g}$ & $\leq 18 \%$ \\
\hline Total Gamma & $\begin{array}{l}\text { High Purity Germanium } \\
\text { Detector }\end{array}$ & sludge Composite & $50 \mu \mathrm{Ci} / \mathrm{g}$ & $\leq 18 \%$ \\
\hline Plutonium-238 & $\begin{array}{l}\text { Separation and Alpha } \\
\text { Spectrometry }\end{array}$ & Sludge Composite & $0.1 \mu \mathrm{ci} / \mathrm{s}$ & $\leq 25 \%$ \\
\hline Plutonium-239/240 & $\begin{array}{l}\text { Separation and Alpha } \\
\text { Spectrometry }\end{array}$ & sludge Composite & $2 \mu \mathrm{ci} / \mathrm{g}$ & $\leq 25 x$ \\
\hline Americium-241 & $\begin{array}{l}\text { Separation and Alpha } \\
\text { Spectrometry/Gamma } \\
\text { Energy Analysis } \\
\end{array}$ & sludge Composite & $2 \mu \mathrm{ci} / \mathrm{g}$ & $\leq 25 \%$ \\
\hline Cobalt -60 & Gamma Energy Analysis & sludge Composite & $0.1 \mu \mathrm{ci} / \mathrm{g}$ & $\leq 25 \%$ \\
\hline Europium-154/155 & Gamma Energy Analysis & Sludge Composite & $5 \mu \mathrm{Ci} / \mathrm{g}$ & $\leq 25 \%$ \\
\hline Uranium & $\begin{array}{l}\text { Laser Induced Kinetic } \\
\text { Phosphorescence }\end{array}$ & sludge Composite & $1,000 \mu \mathrm{g} / \mathrm{g}$ & $\leq 25 x$ \\
\hline Bulk Density & Gravimetric & Sludge Composite & $N / A^{6}$ & $\leq 10 \%$ \\
\hline Consol idation & Centrifugation & Full Segment & N/A & $\leq 10 \%$ \\
\hline Particle size & Laser & Sludge Composite & $2 \mu m^{8}$ & $\leq 18 \%$ \\
\hline
\end{tabular}

1 Other techniques that meet the required uncertainty are also acceptable.

2 All analyses are conducted on honogenized samples except for consolidation.

3 Required sensitivity on a dry basis for solid samples.

4 Values lower than the desired sensitivity do not require this uncertainty.

5 Values outside this $\mathrm{pH}$ range do not require the specified uncertainty.

7 N/A = not appl icable

7 Tests must be conducted on sludge samples before homogenization.

8 An estimate of the total number and mass of particles under $2 \mu \mathrm{m}$ in diameter is required. Determination of particle sizes under $2 \mu \mathrm{m}$ is not necessary. 
WHC-SD-WM-DQ0-007 Rev. 0

This page intentionally left blank. 


\section{CONTENTS}

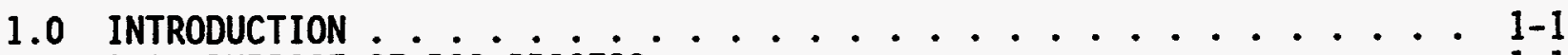

1.1 PURPOSE OF DQO PROCESS .............. 1 . .

1.2 SCOPE OF FERROCYANIDE DQO PROCESS ............ 1-1

2.0 BACKGROUND . . . . . . . . . . . . . . . 2-1

2.1 FERROCYANIDE SAFETY PROGRAM HISTORY .......... 2-1

2.2 RELATIONSHIP OF THE FERROCYANIDE SAFETY PROGRAM TO OTHER TWRS

ELEMENTS ....................... 2-3

3.0 KEY DECISIONS, REQUIRED INPUT, AND BOUNDARIES ......... 3-1

3.1 SAFETY CATEGORIES FOR FERROCYANIDE TANKS ......... 3-1

3.2 DATA REQUIREMENTS FOR TANK CATEGORIZATION . . . . . . . . 3-1

3.2.1 Primary Data Requirements . . . . . . . . . 3-1

3.2.2 Secondary Data Requirements ......... 3-3

3.2.3 Tertiary Data Requirements . . . . . . . 3-5

3.3 BOUNDARIES ........................ 3-7

3.3.1 Sampling Methods . . . . . . . . . . . 3-8

3.3.2 Sample Segment Requirements .......... 3-8

3.3 .3 Sampling Location ............... 3-9

3.3.4 Core Recovery . . . . . . . . . . . . 3-9

4.0 STATEMENT OF THE KEY QUESTIONS AND ANSWERS . . . . . . . . . 4-1

4.1 DESCRIPTION OF DECISION RULES . . . . . . . . . . 4-1

4.2 SAFE VERSUS CONDITIONALLY SAFE OR UNSAFE DECISION RULE ... 4-1

4.3 CONDITIONALLY SAFE VERSUS UNSAFE DECISION RULE . . . . . . 4-1

4.4 DECISION LOGIC . . . . . . . . . . . . . 4-2

5.0 ERROR TOLERANCES ASSOCIATED WITH MEASUREMENTS . . . . . . . 5-1

5.1 DESCRIPTION OF DISCOMFORT CURVES . . . . . . . . . 5-1

5.2 SAFE VERSUS CONDITIONALLY SAFE OR UNSAFE DECISION RULE ... 5-2

5.3 CONDITIONALLY SAFE VERSUS UNSAFE DECISION RULE ...... 5-4

6.0 OPTIMAL SAMPLING DESIGN ................ 6-1

6.1 FACTORS AFFECTING SAMPLING REQUIREMENTS .........

6.1.1 Estimates of Uncertainty from Prior Information . . . 6-1

6.1.2 Number of Cores Required ............ 6-3

6.1.3 Achievable Probabilities of Making Incorrect Decisions - 6-3

6.2 SENSITIVITIES OF NUMBER OF CORES AND RSD CALCULATIONS . . . . 6-4

7.0 CONCLUSIONS ......................... 7-1

7.1 FINDINGS .................... . . . . . .

7.2 RECOMMENDATIONS ......................

8.0 REFERENCES ....................... 8-1

APPENDIXES

A DESCRIPTION OF DQO PROCESS ..............A-1

B FORMULAS AND STATISTICAL ISSUES ............. B-1

C SENSITIVITY CALCULATIONS ............... C-1

D INDEPENDENT REVIEW OF $22 \%$ RSD CALCULATION .......... D-1 


\section{LIST OF FIGURES}

4-1 Moisture Decision RuTe . . . . . . . . . . . . 4-2

4-2 Ferrocyanide DQO Decision Logic ... . . . . . . . . 4-3

4-3 Ferrocyanide DQO Decision Rule Logic . . . . . . . . . . . 4-4

5-1 Discomfort Curve for Ferrocyanide Concentration Used to Show Decision Error Tolerance.............. 5-3

5-2 Moisture Diagram ... . . . . . . . . . 5-5

5-3 Discomfort Curve ................. 5-5

\section{LIST OF TABLES}

3-1 Secondary Data Requirements for Ferrocyanide Tanks . . . . . 3-5

3-2 Tertiary Data Requirements for Ferrocyanide Tanks . . . . . . 3-7

6-1 Calculated Analytical Uncertainties Using Data From Tanks 241-C-109 and 241-C-112 ................. 6-2

6-2 Achievable Probabilities for Decision Error for the Safe Versus Conditionally Safe or Unsafe Decision Rule .......... 6-3

6-3 Achievable Probabilities for Decision Error for the Conditionally Safe Versus Unsafe Decision Rule ............. . 6-4 


\section{LIST OF ACRONYMS}

$\begin{array}{ll}\text { DOE } & \text { U.S. Department of Energy } \\ \text { DQO } & \text { Data Quality Objectives } \\ \text { DSC } & \text { Differential Scanning Calorimetry } \\ \text { EIS } & \text { Environmental Impact Statement } \\ \text { EPA } & \text { U.S. Environmenta1 Protection Agency } \\ \text { GAO } & \text { U.S. General Accounting Office } \\ \text { RSD } & \text { Relative Standard Deviation } \\ \text { SAR } & \text { Safety Analysis Report } \\ \text { SST } & \text { Single-Shell Tank } \\ \text { TOC } & \text { Total Organic Carbon } \\ \text { TWRS } & \text { Tank Waste Remediation System } \\ \text { USQ } & \text { Unreviewed Safety Question }\end{array}$


WHC-SD-WM-DQ0-007 Rev. 0

This page intentionally left blank. 
WHC-SD-WM-DQO-007 Rev. 0

\subsection{INTRODUCTION}

\subsection{PURPOSE OF DQO PROCESS}

The DQO process was developed by the U.S. Environmental Protection Agency (EPA 1987, 1993; Neptune et al. 1990) to provide decision makers with a tool for determining data requirements and their acceptable levels of confidence before sampling occurs. It assists in documenting the procedure used to determine the data requirements, making the data requirements more defensible. The DQO process can be applied to problems involving the collection and use of data and has been extended to the different issues associated with Hanford Site tank waste. The DQO process helps identify and define the type, quantity, and quality of data required. The process consists of seven steps:

- Step 1: State the problem

- Step 2: Identify the decision

- Step 3: Identify the inputs to the decision

- Step 4: Define the study boundaries

- Step 5: Develop a decision rule

- Step 6: Specify acceptable limits on decision errors

- Step 7: Optimize the design

A more detailed description of what each step entails is provided in Appendix A. Sections 2.0 through 6.0 of this report address all seven steps of the $D Q O$ process in sequence.

There are several approaches to organizing and implementing the DQO process for the Hanford Site tanks. The simplest method is to develop DQOs for each of the 177 tanks on a tank-by-tank basis. A better approach is to group the tanks by waste type and safety issue, which is the driver for this DQO process. An issue-based DQO approach guarantees a consistent application of the DQOS for that set of tanks and ensures the transfer of information for all tanks associated with that issue.

The Ferrocyanide DQO process is a continuing effort. Current assumptions (e.g., non-central $t$-distribution of fue $l^{1}$ ) will be further validated and refined as more data from sampling and characterization become available. Consequently, this is a living document, and revisions will be made as new information warrants.

\subsection{SCOPE OF FERROCYANIDE DQO PROCESS}

The primary scope of the Ferrocyanide DQO process is to assist in determining the interim safe storage status of the Ferrocyanide Watch List tanks. Specifically, the Ferrocyanide DQO process defines the type, quantity, and quality of data required to categorize the ferrocyanide tanks as safe, conditionally safe, or unsafe. In addition, this DQO process provides linkage

${ }^{1}$ Defined in Appendix B 
with other safety issues (i.e., transfer of key issues that are outside the scope of this DQO process to other DQO processes to ensure smooth transitions) and Tank Waste Remediation System (TWRS) functional elements.

Although the Ferrocyanide DQO process deals primarily with core sampling, it is not limited to that characterization technique. Historical information, simulant waste studies, and theoretical analyses are also part of this DQO process. This application addresses only the Ferrocyanide Safety Issue. Non-ferrocyanide tanks are covered by the safety screening module (Babad and Redus 1994) or other DQO processes. 
WHC-SD-WM-DQ0-007 Rev. 0

\subsection{BACKGROUND}

\subsection{FERROCYANIDE SAFETY PROGRAM HISTORY}

Various high-level radioactive waste from defense operations has accumulated at the Hanford Site in underground storage tanks since the mid-1940s. During the 1950s, additional tank storage space was required to support the defense mission. To obtain this additional storage volume within a short time period, and to minimize the need for constructing additional storage tanks, Hanford Site scientists developed a process to scavenge ${ }^{137} \mathrm{Cs}$ from tank waste liquids. In implementing this process, approximately 140 metric tons (154 tons) of ferrocyanide were added to waste that was later routed to some Hanford Site single-shell tanks (SST).

Ferrocyanide, in the presence of oxidizing material such as sodium nitrate and/or nitrite, can be made to react exothermically by heating it to high temperatures or by applying an electrical spark of sufficient energy. Under laboratory conditions deliberately created to enhance the potential for reactions, significant exothermic reactions can start as low as $220{ }^{\circ} \mathrm{C}$, but the lowest propagation temperature observed is approximately $250^{\circ} \mathrm{C}$. The reactive nature of ferrocyanide in the presence of an oxidizer has been known for decades, but the conditions under which the compound can undergo endothermic and exothermic reactions have not been thoroughly studied. Because the scavenging process precipitated ferrocyanide from solutions containing nitrate and nitrite, an intimate mixture of ferrocyanides and nitrates and/or nitrites is likely to exist in some regions of the ferrocyanide tanks.

Efforts have been underway since the mid-1980s to evaluate the potential for ferrocyanide reactions in Hanford Site SSTs (Burger 1989, Burger and Scheele 1988). The potential consequences of a postulated ferrocyanide reaction were not evaluated in the safety analyses or safety analysis reports (SARs) applicable to the Hanford Site SSTs. The SARs historically have considered a rapid exothermic reaction from fuel/nitrate reactions as an incredible event, and the consequences of incredible events are not required to be analyzed (WHC 1993).

Although not considered a part of the safety analysis for storage of waste in the SSTs, the 1987 Environmental Impact Statement (EIS), Final Environmental Impact Statement, Disposal of Hanford Defense High-Level Transuranic and Tank Waste, Hanford Site, Richland, Washington (DOE 1987) did include an environmental impact analys is of potential exothermic reactions involving ferrocyanide-nitrate mixtures. The EIS authors speculated that an explosion could occur during mechanical retrieval of saltcake or sludge from a ferrocyanide waste tank. The EIS authors concluded that this worst-case accident could create enough energy to release radioactive material to the atmosphere through ventilation openings, exposing persons offsite to a short-term radiation dose of approximately $200 \mathrm{mrem}$. A U.S. General Accounting Office (GAO) study (Peach 1990) postulated a greater worst-case accident, with independently calculated doses of one to two orders of magnitude greater than in the EIS. Coupling the ferrocyanide concerns with concerns about high organic concentrations and potential hydrogen accumulations in other Hanford Site high-level waste tanks, the DOE 
established the High-Level Radioactive Waste Tanks Task Force and Tanks Advisory Panel in August 1990. These two groups were formed to ensure that all safety concerns with high-level waste tanks at DOE sites are identified and addressed in a systematic and timely manner.

The initial focus of the task force and advisory panel was on the Hanford Site Flammable Gas and Ferrocyanide Safety Issues. In September 1990, a special Hanford Site ferrocyanide task team was commissioned by Westinghouse Hanford Company to address all issues involving the ferrocyanide tanks, including the consequences of a potential accident.

The Ferrocyanide Safety Issue is a result of a combination of factors, beginning with the safety studies performed as precursors to using the ferrocyanide scavenging flowsheets. These studies did not address ultimate disposal of the ferrocyanide solids, and were not performed to the conservative standards used today. In addition, no rigorous inventory was kept of the ferrocyanide or other chemicals added to the tanks. Subsequent safety studies determining the risk of adding other chemicals were either not performed, or were performed to less conservative standards. Monitoring systems, such as temperature measurement instrumentation, were allowed to be disconnected and fall into disrepair because the potential hazard was not highlighted.

Although the EIS authors estimated the consequences from a hypothetical explosion, the GAO disagreed with the assumptions used for the dose consequence calculations. Work performed by Pacific Northwest Laboratory in 1984-85 (Burger 1989) identified a potential safety problem, but no funding was provided until 1989 to study the Ferrocyanide Safety Issue. An additional issue was subsequently communicated about the assumed radioactive material source term (release fraction) resulting from a hypothetical explosion (Peach 1990).

In October 1990 (Deaton 1990), the Ferrocyanide Safety Issue was declared an unreviewed safety question (USQ ${ }^{2}$ ) because the safety envelope for these tanks was no longer bounded by the existing safety analysis report (Smith 1986). At this time, the Ferrocyanide Watch List was created. In 1991, using process knowledge, process records, transfer records, and log books, 24 Hanford Site tanks were identified as potentially containing 1,000 g-moles (465 1b) or more of ferrocyanide [as the $\mathrm{Fe}(\mathrm{CN})_{6}^{4-}$ anion]. These tanks were placed on the Ferrocyanide Watch List because of the USQ. Re-examination of the historical records (Borsheim and Simpson 1991) indicated that 6 of the 24 tanks do not

\footnotetext{
${ }^{2}$ An Unreviewed Safety Question, as defined by DOE Orders 5480.5 (DOE 1986) and 5480.21 (DOE 1991), is determined as follows. "A proposed change, test or experiment shall be deemed to involve an USQ if the following apply:

a. The probability of occurrence or the consequences of an accident or malfunction of equipment important to safety, evaluated previously by safety analysis will be significantly increased, or

b. A possibility for an accident or malfunction of a different type than any evaluated previously by safety analysis will be created which could result in significant safety consequences."
} 
contain the requisite 1,000 g-moles of ferrocyanide and should not have been included on the Watch List. Four of the 6 tanks were removed from the Watch List in June 1993 (Meacham et al. 1993) and removal of the other two tanks is pending (Borsheim et al. 1993).

The Ferrocyanide USQ was closed on March 1, 1994 by the DOE Assistant Secretary for Environmental Restoration and Waste Management (Sheridan 1994). Closure of the Ferrocyanide USQ was based on safety criteria proposed by Westinghouse Hanford Company and concurred on by outside reviewers and reviewers within DOE. This was the first USQ closure in the current Waste Tank Safety Program since the Watch List was created in 1990.

\subsection{RELATIONSHIP OF THE FERROCYANIDE SAFETY PROGRAM TO OTHER TWRS ELEMENTS}

The primary focus of the Ferrocyanide Safety Program is within the Waste Tank Safety Programs element of TWRS. As the DQO processes for the other TWRS functional elements are conducted, a question of ferrocyanide waste compatibility with the selected tank transfers and processes will need to be addressed. For example, if the conditions defined for safe or conditionally safe are compromised during characterization, retrieval, or pretreatment, then the safety consequences and operating conditions will need to be defined.

A safety screening module has been developed to evaluate all tanks for potential safety issues (Babad and Redus 1994). Therefore, a Ferrocyanide Watch List tank may also be evaluated for other safety issues. Section 4.0 briefly discusses the safety screening module. 
WHC-SD-WM-DQ0-007 Rev. 0

This page intentionally left blank. 
WHC-SD-WM-DQO-007 Rev. 0

\subsection{KEY DECISIONS, REQUIRED INPUT, AND BOUNDARIES}

\subsection{SAFETY CATEGORIES FOR FERROCYANIDE TANKS}

The strategy for determining the safety status of Ferrocyanide Watch List tanks places them into one of three categories: safe, conditionally safe, or unsafe. Numerical criteria for the three safety categories have been developed and selected for ferrocyanide tanks based on empirical data and theoretical calculations (Postma et al. 1994). Conservative values were selected to provide a margin of safety between the tank conditions and the conditions necessary to support a propagating reaction.

A safe ferrocyanide tank is defined as having a concentration of fuel less than or equal to 8 wt\% disodium nickel ferrocyanide $\left[\mathrm{Na}_{2} \mathrm{NiFe}(\mathrm{CN})_{6}\right]$ on an energy equivalent basis (i.e., $\leq 0.48 \mathrm{MJ} / \mathrm{kg}$ or $115 \mathrm{cal} / \mathrm{g}$ ). Under this condition, the concentration of water and oxidizers and the temperature of the waste are not limiting. Monitoring and controls are not required to address the ferrocyanide hazard during interim storage.

A conditionally safe ferrocyanide tank is defined as having a fuel concentration greater than $8 \mathrm{wt} \%$ and a moisture content greater than $4 / 3$ (Fuel wt\% - $8 w t \%$ ). Under these conditions, the concentration of oxidizers is not limiting. Monitoring and controls may be required to limit the loss of moisture, and to ensure that the waste temperature does not exceed $90-{ }^{\circ} \mathrm{C}$.

Tanks categorized as either safe or conditionally safe cannot support an exothermic propagating reaction. An unsafe ferrocyanide tank does not meet the criteria for the safe or conditionally safe categories. For tanks in the unsafe category, monitoring and controls are required to avoid conditions that could lead to reaction ignition. Modifications in waste state are required to remove a tank from the unsafe category.

\subsection{DATA REQUIREMENTS FOR TANK CATEGORIZATION}

\subsubsection{Primary Data Requirements}

Data on fuel and moisture concentration are necessary to categorize a ferrocyanide tank as safe, conditionally safe, or unsafe. Primary data are required from the $1 \mathrm{ab}$ within 45 days of receipt of the last sample (e.g., if two cores are taken, after receipt of the second core). The numerical value of the fuel concentration criterion is calculated on the basis of energy content, in $\mathrm{MJ} / \mathrm{kg}$ of dry waste. To judge whether waste meets the concentration criterion, the exothermic energy $(\mathrm{MJ} / \mathrm{kg})$ must be determined experimentally. The equivalent ferrocyanide concentration is then calculated by dividing the measured exothermic energy by the reaction energy of dry 
$\mathrm{Na}_{2} \mathrm{NiFe}(\mathrm{CN})_{6}$. The reaction energy of dry (zero free water ${ }^{3}$ ) $\mathrm{Na}_{2} \mathrm{NiFe}(\mathrm{CN})_{6}$ was determined experimentally (Postma et al. 1994) to be $6 \mathrm{MJ} / \mathrm{kg}(1,430 \mathrm{cal} / \mathrm{g}$ ).

For example, if a waste sample exhibited a reaction exotherm of $0.6 \mathrm{MJ} / \mathrm{kg}$ $(143 \mathrm{cal} / \mathrm{g})$, the energy equivalent ferrocyanide concentration is:

$$
\begin{gathered}
\frac{0.6 \mathrm{MJ} / \mathrm{kg} \text { of waste }}{6 \mathrm{MJ} / \mathrm{kg} \mathrm{of} \mathrm{Na}_{2} \mathrm{NiFe}(\mathrm{CN})_{6}} \times 100 \mathrm{wt}=10 \mathrm{wt} \mathrm{Na}_{2} \mathrm{NiFe}(\mathrm{CN})_{6} \\
\text { or } \\
\frac{143 \mathrm{cal} / \mathrm{g} \text { of waste }}{1430 \mathrm{Cal} / \mathrm{g} \mathrm{of} \mathrm{Na}_{2} \mathrm{NiFe}_{(\mathrm{CN})_{6}}} \times 100 \mathrm{wt}=10 \mathrm{wtz} \mathrm{Na}_{2} \mathrm{NiFe}(\mathrm{CN})_{6} .
\end{gathered}
$$

The energy basis permits accounting for all reactants that might be present. Examples of potential reactants not explicitly identified in the concentration criteria are sodium sulfide and numerous organic substances that may be present at low concentrations in ferrocyanide wastes.

Differential Scanning Calorimetry (DSC) can be used to quantify the exothermic energy content of samples. For samples whose energy content approaches the 8 wt\% fuel criterion, additional testing by adiabatic calorimetry is recommended. Specifically, if the energy content is greater than $0.3 \mathrm{MJ} / \mathrm{kg}$ $(75 \mathrm{cal} / \mathrm{g})$, the Ferrocyanide Safety Program shall be notified and a decision whether to run adiabatic calorimetry analyses will be made at that time. The reasons for adiabatic calorimetry testing are twofold. First, relatively large samples (10 grams or more) are tested. This provides assurance that the sample tested is representative of the bulk of the sampled material. Second, the observed self-heating behavior is direct evidence of the kinetics and energetics of the reactions in dried waste. This information would allow for a more accurate comparison of energy content with the safe criterion. It would also provide input to studies designed to confirm the validity of the criteria that are presently based on simulants.

The ferrocyanide concentration criterion is applied to relatively thin layers of ferrocyanide waste. The measured concentration in each quarter segment layer, a 12-cm (4.8-in.)-high cylinder of waste removed by core sampling ${ }^{4}$, is used to categorize the tank. It is recognized that the homogenized quarter segment samples would not permit the detection of thinner layers that could have higher-than-average concentration. The safety implications of not detecting peak concentrations in layers thinner than $12 \mathrm{~cm}$ are discounted for the following reasons:

- Studies of historical process information (Simpson et al. 1993a, 1993b, Borsheim and Simpson 1991) indicate that individual batches produced layers thicker than $12 \mathrm{~cm}$ for U Plant and T Plant flowsheets. U Plant and $T$ Plant batches were settled sequentially, resulting in ferrocyanide

3 Free water is defined as the water removed by drying at $120{ }^{\circ} \mathrm{C}$ for 18 hours.

4 Concentrations deduced from other reliable characterization data are also acceptable. 
sludge beds from 34 to $260 \mathrm{~cm}$ (13 to $100 \mathrm{in.)}$ deep. For these wastes (comprising $74 \%$ of all ferrocyanide waste at the Hanford Site), 12-cm quarter segments should detect the highest concentration layer.

- For the more concentrated In Farm sludges, individual batches could have deposited sludge layers an estimated 3.6 to $6.1 \mathrm{~cm}(1.4$ to $2.4 \mathrm{in}$.) thick (Simpson et a1. 1993a). Batches were settled sequentially, resulting in ferrocyanide sludge beds from 91 to $120 \mathrm{~cm}$ (36 to $47 \mathrm{in.}$ ) deep. Thus a quarter segment (12 cm high) would theoretically intercept two to four layers. Homogenization of the quarter segment sample would average ferrocyanide concentrations for two to four batches. Based on simulants, the In Farm 1 and In Farm 2 sludges had maximum concentrations of 25.5 and 22.6 wt\% $\mathrm{Na}_{2} \mathrm{NiFe}(\mathrm{CN})_{6}$, respectively (Postma et al. 1994). The maximum $(25.5 \%)$ is only $6 \%$ larger than the average $(24.05 \%)$, so an analysis of two mixed layers (In Farm 1 and In Farm 2) would not differ significantly from that of the richer layer.

- Processes have occurred that would reduce concentration gradients during storage, including: (1) convective mixing in receiver tanks caused by the momentum of in-flowing sludge making up each batch; (2) diffusion during $35+$ years of storage; and (3) degradation by chemical reactions that proceed fastest in highest-concentration sludges.

Based on the foregoing discussion, large-concentration gradients are not expected to exist within quarter segments removed from sludge comprised of two to four layers. However, it should be noted that a significant safety margin exists between the $8 \mathrm{wt} \%$ fuel concentration criterion and the experimentally determined threshold for propagation $(-15 w t \%)$. Therefore, relatively large gradients in concentration could be tolerated without posing a safety hazard.

The moisture criterion, like the ferrocyanide concentration criterion, is applied on a layer-by-layer basis. Each layer would be identified by quarter segment analysis. The minimum required moisture in a given quarter segment (or layer) is given by the equation:

$$
\text { wt: Free water } \left.\geq \frac{4}{3} \text { (wtz Fuel - } 8 w t z\right) \text {. }
$$

Thermogravimetric analysis is currently recommended for determining moisture concentration; however, it is recognized that other techniques (e.g., Raman spectroscopy, near-infrared spectroscopy, neutron diffusion, etc.) are being developed. Once validated, techniques that meet the desired uncertainty criterion are acceptable.

\subsubsection{Secondary Data Requirements}

There are several data requirements (Table 3-1) for the Ferrocyanide DQO process that are secondary to the key data needs (i.e., fuel and moisture concentration). Secondary data requirements are not directly involved in the decision rule logic for ferrocyanide waste, but will expedite final resolution of the Ferrocyanide Safety Issue. Secondary data are required from the lab within 216 days of receipt of the last sample. A description of the secondary data requirements follows: 
- Temperature of the waste is an important data requirement that is used in support of the decision whether a tank is conditionally safe or unsafe. If the waste temperature is greater than $90^{\circ} \mathrm{C}$, the fuel concentration is greater than 8 wt\%, and the moisture content is greater than $4 / 3$ (wt\% fuel - $8 w t \%$ ), then the tank is categorized as unsafe for storage, and mitigation may be required. This is because rapid moisture loss could not be ruled out for waste temperatures greater than $90^{\circ} \mathrm{C}$. Temperature is not a core sample data value, but is obtained from instrument tree measurements. Any validated tank temperature found to be increasing would require actions as mandated by the Ferrocyanide Action Plan (Fowler 1994).

- Nickel is a signature analyte of the nickel ferrocyanide scavenging process (the only source of added nickel) and indicates how much ferrocyanide was originally present in the waste. Nickel concentrations should be determined by inductively coupled plasma analysis by either acid digestion or fusion preparations (whichever is more accurate). Non-nickel crucibles (e.g., platinum, zirconium, etc.) must be used during this analysis to reduce analytical bias.

Measurement of nickel concentration offers evidence of ferrocyanide waste aging (Babad et al. 1993, Lilga et al. 1993). Aging is important because it helps reconcile why ferrocyanide concentrations found in the tanks today are lower than anticipated. For example, tanks 241-C-109 and 241-C-112 (Simpson et a1. 1993a, 1993b) contain about an order of magnitude less ferrocyanide than predicted by process flowsheets (Borsheim and Simpson 1991). Comparison of the original values with current total cyanide measurements gives an assessment of the degree of aging that has occurred during storage.

- Total cyanide analysis provides information on fuel characterization. Without this measurement, it would be difficult to confirm whether a tank belongs on the Ferrocyanide or Organic Watch List (possibly both). This is important because these tanks are governed by sightly different sets of safety criteria (Postma et a1. 1994, Babad and Turner 1993) and may require different monitoring and control procedures.

Total cyanide also offers corroborative evidence of the total fuel content of the waste. Although not part of the decision rule, total cyanide concentrations greater than $3.9 \mathrm{wt} \%$ [this corresponds to a $\mathrm{Na}_{2} \mathrm{NiFe}(\mathrm{CN})_{6}$ concentration of $8 \mathrm{wt} \%$ ] shall be flagged to the Ferrocyanide Safety Program. Total cyanide is measured by dissolving the waste sample in an ethylenediaminetetraacetic acid/ethylenediamine solution, followed by argentometric titration or other suitable detection technique.

- Total organic carbon (TOC) in the waste is also a secondary measurement that provides more information on the fuel content of the waste. Direct persulfate oxidation is recommended to determine TOC; however, other techniques that meet the desired analytical uncertainty are also acceptable. Together, the TOC measurement and the ferrocyanide concentration provide a complete set of data on the fuel content of the waste. 
- Strontium-90 and cesium-137 are the major heat-producing radionuclides in the ferrocyanide tanks. These analyses are conducted on homogenized half segments for sludge and saltcake. Strontium-90 and cesium-137 analyses offer confirmation of heat load and hot spot models developed for the Ferrocyanide Safety Program. Hot spot and heat load models are important in establishing the probability of a tank moving from the conditionally safe category to the unsafe category because of water evaporation.

Table 3-1. Secondary Data Requirements for Ferrocyanide Tanks.

\begin{tabular}{|c|c|c|c|c|}
\hline Analyte & Analytical Method ${ }^{1}$ & Sample $e^{2}$ & $\begin{array}{l}\text { Required } \\
\text { Sensitivity }\end{array}$ & $\begin{array}{l}\text { Required } \\
\text { Analytical } \\
\text { Uncertainty }\end{array}$ \\
\hline Tank Temperature & Thermocouple & $\bar{N} / A^{5}$ & $90^{\circ} \mathrm{C}$ & $\leq 10 \%$ \\
\hline Nickel & $\begin{array}{l}\text { Inductively Coupled } \\
\text { Plasma }\end{array}$ & $\begin{array}{c}\text { (Siludge Only) } \\
\text { (3)-Segment }\end{array}$ & $500 \mu \mathrm{g} / \mathrm{g}$ & $\leq 10 \%$ \\
\hline Total Cyanide & Direct Analyses & $\begin{array}{l}\frac{1}{2} \text {-Segment } \\
\text { \& Liquid }\end{array}$ & 0.5 wt\% & $\leq 10 \%$ \\
\hline $\begin{array}{l}\text { Total Organic } \\
\text { Carbon }\end{array}$ & Furnace Oxidation & $\frac{1}{\xi}$-Segment & 1.0 wt\% & $\leq 10 \%$ \\
\hline Cesium-137 & $\begin{array}{l}\text { Gamma Energy } \\
\text { Analys is }\end{array}$ & $\begin{array}{l}\frac{1}{2}-\text { Segment } \\
\text { \& Liquid }\end{array}$ & $50 \mu \mathrm{Ci} / \mathrm{g}$ & $\leq 10 \%$ \\
\hline Stront ium-90 & Beta Radiochemistry & $\begin{array}{l}\frac{1}{2}-\text { Segment } \\
\text { \& Liquid }\end{array}$ & $50 \mu \mathrm{Cj} / \mathrm{g}$ & $\leq 10 \%$ \\
\hline
\end{tabular}

1 Other techniques that meet the required uncertainty also are acceptable.

2 A11 analyses are conducted on homogenized samples.

3 All required sensitivities are reported on a dry basis for solid samples.

4 Values less than the required sensitivity do not require the specified analytical uncertainty.

$5 \mathrm{~N} / \mathrm{A}=$ not applicable

6 Non-nickel crucibles must be used to reduce the potential for analytical bias.

\subsubsection{Tertiary Data Requirements}

Data that are important for resolving the Ferrocyanide Safety Issue, but do not have the urgency of the data previously described, are considered tertiary data requirements. Tertiary data include rheological and physical properties, cations, anions, and radiochemistry. These data are required from the $1 \mathrm{ab}$ within 216 days of receipt of the last sample. The required analyses are presented in Table 3-2.

All tertiary analyses are conducted on sludge only, and are not required for saltcake. Consolidation measurements are performed on a full segment basis, before homogenization. The remaining tertiary analyses are performed on a core composite basis. For example, if two core samples were taken from a tank, a sludge composite would be made for each core and the tertiary analyses (excluding consolidation) would be performed twice. Some of the tertiary 
analyses are performed on the drainable liquid from the cores. The drainable liquid from each core segment is combined to form a single liquid composite for the core.

Analyses for consolidation and particle size will be reviewed based on results from three ferrocyanide tanks. If it is confirmed that the particle size is small (1ess than $2 \mu \mathrm{m}$ ) and that the waste retains considerable water after centrifuging, these two analyses will be dropped for future ferrocyanide tanks.

Tertiary data are required for a variety of purposes in the Ferrocyanide Safety Program. Rheological and physical measurements are required to validate waste dryout (moisture retention and hot spot) models, and to evaluate the aging model. Waste dryout models are important in establishing the probability of a tank moving from the conditional7y safe to the unsafe category because of water evaporation. Validation of the waste aging model provides an important linkage between the fuel value originally placed in the ferrocyanide tanks and the current analyses. Radiological and chemical analyses are also required to validate waste aging models, and to confirm waste transfer histories. Confirmation of waste transfer histories is important because these histories were used to identify which tanks belonged on the Ferrocyanide Watch List.

The rheological analysis required by the Ferrocyanide Safety Program is consolidation. Consolidation is shrinkage of the waste matrix as a result of moisture loss. This parameter is required to predict moisture retention of the waste matrix under various dryout or drainage scenarios. Consolidation can be determined by centrifugation of small non-homogenized samples (about 2 to 3 grams) in open-bottom tubes containing fritted giass filters. This analysis should be conducted on a full segment basis (i.e., $48 \mathrm{~cm}$ [19 in.]), and is not performed on saltcake samples. The sample is subjected to 500 gravities ( \pm 50 gravities) of force until equilibrium is reached (i.e., no more water flows from the sample). The mass of fluid loss from the sample is determined at different time intervals so that a consolidation index can be established.

For example, samples from tank 241-T-111 (a non-ferrocyanide tank) reached equilibrium in about 10 hours of centrifuging. This was quite similar to the results seen for ferrocyanide simulants. Therefore, mass loss should be measured every half hour for the first 4 hours, then every hour up to 10 hours. A final point should be measured at 24 hours. This example is not a rigid procedure for measuring consolidation; however, it does provide a starting point for this measurement. If considerably longer or less time is required for the sample to reach equilibrium, then the time intervals at which data will be taken will change. Additional techniques are available for

\footnotetext{
${ }^{5}$ The need for consolidation and particle size analyses will be reviewed based on results from three ferrocyanide tanks. If it is confirmed that the particle size is small (less than $2 \mu \mathrm{m}$ ) and that the waste retains considerable water after centrifuging, then these two analyses will be dropped for future ferrocyanide tanks.
} 
measuring consolidation, and other techniques that meet the specified analytical uncertainty are also acceptable.

Table 3-2. Tertiary Data Requirements for Ferrocyanide Tanks.

\begin{tabular}{|c|c|c|c|c|}
\hline Analyte & Analytical Method 1 & Sample ${ }^{2}$ & $\begin{array}{l}\text { Required } \\
\text { Sensitivity }\end{array}$ & $\begin{array}{l}\text { Required } \\
\text { Anstyt ical } \\
\text { Uncertainty }\end{array}$ \\
\hline $\begin{array}{l}\text { Aluminum, Calcium, Iron, } \\
\text { Phosphorus, Sodium }\end{array}$ & $\begin{array}{l}\text { Induct ively Coupled } \\
\text { Plasma }\end{array}$ & $\begin{array}{l}\text { Sludge Composite } \\
\text { Drainable Liquid }\end{array}$ & $500 \mu \mathrm{g} / \mathrm{g}$ & $\leq 25 \%$ \\
\hline $\begin{array}{l}\text { Chloride, Fluoride, Nitrate, } \\
\text { Nitrite, Phosphate }\end{array}$ & Ion Chromatography & $\begin{array}{l}\text { Sludge Composite } \\
\text { Drainable Liquid }\end{array}$ & $500 \mu g / g$ & $\leq 25 \%$ \\
\hline pH & Ion Selective Electrode & Drainable Liquid & $4-12$ & $\pm 0.5^{5}$ \\
\hline Total Carbon & Coulometric Detection & Sludge Composite & $1,200 \mu g / g$ & $\leq 25 x$ \\
\hline Total Inorganic Carbon & Coulometric Detection & sludge Composite & $1,200 \mu \mathrm{g} / \mathrm{g}$ & $\leq 25 \%$ \\
\hline Total Alpha & Proportional Counting & sludge Composite & $2 \mu \mathrm{Ci} / \mathrm{g}$ & $\leq 18 \%$ \\
\hline Total Beta & Proportional Counting & Sludge Composite & $50 \mu \mathrm{mi} / \mathrm{g}$ & $\leq 18 x$ \\
\hline Total Gamma & $\begin{array}{l}\text { High Purity Germanium } \\
\text { Detector }\end{array}$ & sludge Composite & $50 \mathrm{\mu ci} / \mathrm{g}$ & $\leq 18 \%$ \\
\hline Plutonium-238 & $\begin{array}{l}\text { Separation and Alpha } \\
\text { Spectrometry }\end{array}$ & sludge Composite & $0.1 \mu \mathrm{Ci} / \mathrm{g}$ & $\leq 25 \%$ \\
\hline Plutonium-239/240 & $\begin{array}{l}\text { Separation and Alpha } \\
\text { Spectrometry }\end{array}$ & Sludge Composite & $2 \mu \mathrm{Ci} / \mathrm{g}$ & $\leq 25 \%$ \\
\hline Americium-241 & $\begin{array}{l}\text { Separation and Alpha } \\
\text { Spectrometry/Gamma } \\
\text { Energy Analysis }\end{array}$ & sludge Composite & $2 \mu \mathrm{ci} / \mathrm{g}$ & $\leq 25 \%$ \\
\hline Cobalt -60 & Ganma Energy Analysis & Sludge Composite & $0.1 \mu \mathrm{Ci} / \mathrm{g}$ & $\leq 25 \%$ \\
\hline Europium-154/155 & Gamma Energy Analysis & Sludge Composite & $5 \mu \mathrm{Ci} / \mathrm{g}$ & $\leq 25 \%$ \\
\hline Uranium & $\begin{array}{l}\text { Laser Induced Kinetic } \\
\text { Phosphorescence }\end{array}$ & Sludge Composite & $1,000 \mu / g / g$ & $\leq 25 \%$ \\
\hline Bulk Density & Gravimetric & sludge Composite & $N / A^{6}$ & $\leq 10 \%$ \\
\hline Consol idation & Centrifugation & Full Segment ${ }^{7}$ & $N / A$ & $\leq 10 \%$ \\
\hline Particle size & Laser & Sludge Composite & $2 \mu m^{8}$ & $\leq 18 x$ \\
\hline
\end{tabular}

1 other techniques that meet the required uncertainty are also acceptable.

2 All analyses are conducted on homogenized samples except for consolidation.

3 Required sensitivity on a dry basis for solid samples.

4 Values lower than the desired sensitivity do not require this uncertainty.

Values outside this pH range do not require the specified uncertainty.

6 N/A = not appl icable

7 Tests must be conducted on sludge samples before homogenization.

8 An estimate of the total number and mass of particles under $2 \mu \mathrm{m}$ in diameter is required. Determination of particle sizes under $2 \mathrm{\mu m}$ is not necessary.

\subsection{BOUNDARIES}

When defining key decisions and data requirements, the populations that will be characterized through sampling must be specified, and decision rules will be applied to each of these defined populations. Several factors are important in defining the populations to be characterized, including sampling methods, sample segment requirements, riser location considerations, and core recovery issues. 


\subsubsection{Sampling Methods}

Presently, the most reliable data for categorizing ferrocyanide tanks are obtained from sampling. This includes rotary-mode core sampling, push-mode core sampling, and auger ${ }^{6}$ sampling. However, it is recognized that in situ technologies (e.g., cone penetrometers) may eventually replace the necessity for core sampling.

General sampling information is documented in a report by Bell (1994). Historical information is valuable, but the detailed data required to confidently categorize the tanks are generally not available without obtaining samples from the tanks. The one exception to using core sample information is in measuring temperature. Temperatures are measured using data from instrument trees placed inside the tanks.

\subsubsection{Sample Segment Requirements}

Homogenized quarter segments will be the units to be characterized for the primary data requirements in sludge layers. Rationale for the quarter segment basis is presented in Section 3.2.1, and in more detail in Postma et al. (1994). The quarter segment basis for sludge layers will be reviewed after sampling and analyses of three to five ferrocyanide tanks. If aging (degradation) of the ferrocyanide is confirmed by analyses of these tanks, then the quarter segment analytical basis may be relaxed to half or full segments.

Some ferrocyanide tanks contain hard saltcake layers that were formed after the ferrocyanide scavenging campaigns. These saltcake layers contain little or no ferrocyanide. Therefore, homogenized half segments will be units to be characterized for the primary data requirements in the saltcake layer. The half segment basis for sludge layers will also be reviewed after results are available for three to five ferrocyanide tanks. If very low energetics are found in the saltcake for these tanks, the half segment analytical basis may be relaxed to full segments.

For the secondary data requirements, homogenized half segments will be units to be characterized. The exception to this is nicke1, which is analyzed on a quarter segment basis in sludge layers (note: nickel is not an analyte of saltcake layers). The homogenized half segment (quarter segment for nickel) basis for sludge and saltcake will be reviewed after analyses of three to five ferrocyanide tanks. If aging is confirmed by analyses of these tanks, then the half segment basis may be relaxed to full segments.

All tertiary analyses are conducted only on sludge and not saltcake. Consolidation measurements are performed on a full segment basis, before homogenization. The remaining tertiary analyses are performed on a core composite basis. Some of the tertiary analyses are performed on the drainable

6 The ferrocyanide sludge bed must be very shallow, or the waste viscous enough not to slump into the auger hole during successive samplings. 
liquid from the cores. The drainable liquid from each core segment should be combined to form a single liquid composite for the core, similar to the process for the sludge composites.

\subsubsection{Sampling Location}

Investigation of the current use and location of the risers associated with each tank can determine if current available risers are adequate, or if other risers would need to be cleared of equipment to allow sampling. It may also be determined that new risers would have to be created (an extreme case). An analysis of the available risers for the 20 tanks currently on the Ferrocyanide Watch List indicates that some of the tanks may require removal of equipment or obstructions to prepare them for sampling depending on the number of cores required. Where possible, sampling locations should be chosen to increase the likelihood for obtaining samples that represent the true spatial variations within a tank (e.g., opposite sides or side-center for two cores, side-center-side for three cores).

\subsubsection{Core Recovery}

Characterization of any population requires that samples obtained be representative of the population. This leads into a discussion of acceptable core recovery and sample bias. Core recovery is only important because of the desire to bound potential bias, and it is not a foregone conclusion that poor recovery is equivalent to a large bias. That is, if one is reasonably assured that a partial sample is representative, then only enough sample to perform the required analyses is needed. Therefore, there exists no standard for core recovery, and a definition of acceptable core recovery must be based on specific assumptions, prior knowledge, and/or engineering judgement.

A11 sampling requirements outlined in this document assume that a sample is representative. An argument on acceptable core recovery is not presented in this revision of the DQO; however, core recovery will be addressed in a future revision or in other documents. In summary, cores will be obtained from each tank. Material within each quarter segment of sludge (half segments for saltcake layers) will be homogenized, and a sample will be obtained from each homogenized quarter segment. These quarter segment samples (half segments or core composites) will be analyzed for the analytes specified in Section 3.2. Where applicable, analytical results for quarter segments 1 ayers ${ }^{7}$ will be compared against the decision rule criteria.

${ }^{7}$ Quarter segment samples from the same vertical location (i.e., depth) in the tank are used to characterize a layer. 
WHC-SD-WM-DQO-007 Rev. 0

This page intentionally left blank. 
WHC-SD-WM-DQO-007 Rev. 0

\subsection{STATEMENT OF THE KEY QUESTIONS AND ANSWERS}

\subsection{DESCRIPTION OF DECISION RULES}

In the previous sections, the first four steps of the DQO process have been documented. Specifically, the primary measurements of concern and the important questions to be addressed have been delineated. In Step 5 of the DQO process, a decision rule is formulated. To formulate this decision rule, it is necessary to assume that the tank characteristics are known. Under this assumption of no uncertainty, the outputs from the previous DQO steps are integrated into an unambiguous "If...then..." statement that outlines the conditions under which alternative actions will be chosen. Two decision rules were developed for the ferrocyanide tank safety issue: (1) safe versus conditionally safe or unsafe, and (2) conditionally safe versus unsafe.

\subsection{SAFE VERSUS CONDITIONALLY SAFE OR UNSAFE DECISION RULE}

The ferrocyanide concentration, on a quarter segment layer basis, was chosen to distinguish between the safe and either conditionally safe or unsafe categories. The decision rule states:

- If the fuel concentration average for all homogenized quarter segment sludge layers (half segment for saltcake) is less than or equal to 8 wt\% as disodium nickel ferrocyanide $\left[\mathrm{Na}_{2} \mathrm{NiFe}(\mathrm{CN})_{6}\right]$ on an energy equivalent basis (i.e., $115 \mathrm{cal} / \mathrm{g}$ of dry material), then the tank is categorized as safe.

The rationale for this decision rule and the particular threshold of 8 wt\% fuel is detailed in a separate report (Postma et al. 1994). If the fuel concentration is less than 8 wt\%, then insufficient fuel would be present to sustain a propagating reaction. However, this value is extremely conservative and empirical results using waste simulants indicate that almost twice this fuel concentration (approximately 15 wt\% ferrocyanide) is necessary to sustain a propagating reaction. The conservatism of this decision rule as it affects decision error tolerances is further considered in Section 5.0 of this report.

\subsection{CONDITIONALLY SAFE VERSUS UNSAFE DECISION RULE}

If the concentration of fuel is greater than $8 \mathrm{wt} \%$, other parameters must be considered to determine whether the tank can be categorized as conditionally safe or must be categorized as unsafe (an unsafe categorization would require mitigation actions). The parameter of concern for this decision rule is moisture content. The decision rule states the following:

- If the fuel concentration average in any homogenized quarter segment sludge layer (half segment for saltcake) is greater than 8 wt\% and if the wt\% free water is greater than $4 / 3$ (wt\% fuel - 8 wt\%), then the tank is categorized as conditionally safe. Tanks with greater than 8 wt\% fuel that have less than the specified free water are categorized as unsafe. 
This decision rule (see Figure 4-1) is dependent on two parameters, moisture content and fuel concentration. The detail rationale for this decision rule is also provided in Postma et a1. (1994). As the fuel concentration increases above $8 \mathrm{wt} \%$, the required moisture content also increases, ensuring that no propagating reaction occurs. Conservatism is inherent in this decision rule. For example, at $26 \mathrm{wt} \%$ fue 1 , the corresponding moisture criterion is 24 wt\%. However, experiments have shown that $12 \mathrm{wt \%}$ moisture will prevent propagating reactions in simulants containing 26 wt\% $\mathrm{Na}_{2} \mathrm{NiFe}(\mathrm{CN})_{6}$ (Fauske 1992, Jeppson and Wong 1993). This conservatism is considered in determining appropriate decision error tolerances as outlined in Section 5.0 of this report.

Figure 4-1. Moisture Decision RuTe.

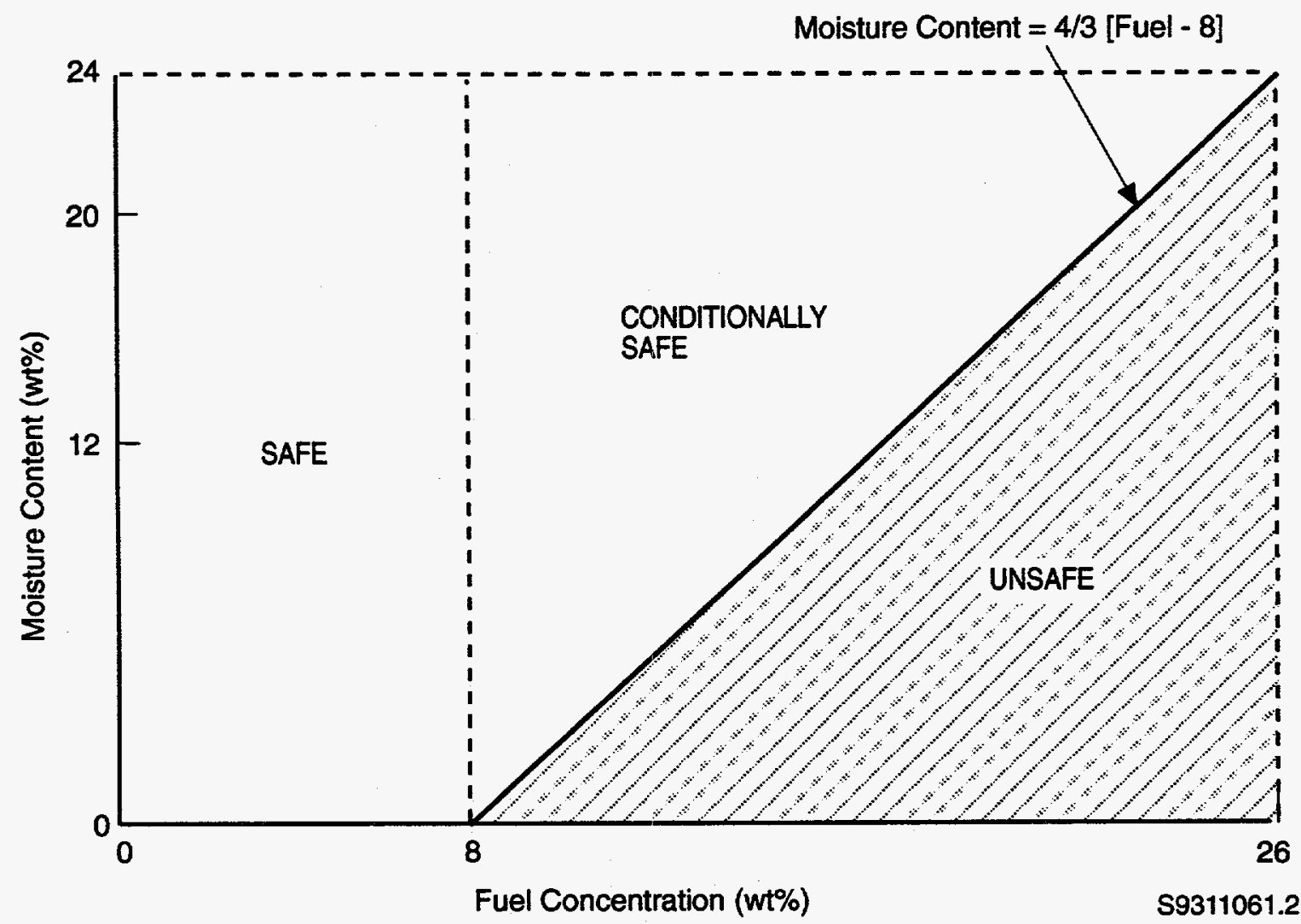

\subsection{DECISION LOGIC}

To fully understand the Ferrocyanide DQO decision logic, one must understand how it relates to the general tank characterization DQO strategy. Figure 4-2 outlines the general tank characterization DQO logic and defines the relationships between several safety issue DQOS, TWRS functional element DQOS, and the safety screening module.

Based on historical data and/or data available from safety screening module campaigns, tanks will be identified as having or not having significant safety issues. For those tanks that violate the safety screening criteria, characterization requirements are defined by the appropriate DQOS for that specific safety issue. For example, 20 tanks are on the Ferrocyanide Watch List based on historical data. Other tanks could potentially be added to this 
list if the screening module criteria for ferrocyanide waste were violated. For these tanks on the Ferrocyanide Watch List, waste characterization requirements are outlined in this DQO report. If some of these tanks are suspected to have other safety issues, the data requirements outlined through the $D Q O$ process for those safety issues would al so be essential for developing tank sampling and analysis plans. Finally, depending on time and resource considerations, data requirements from other TWRS functional elements (i.e., retrieval, pretreatment, and disposal) would also be considered.

The Ferrocyanide Safety Issue decision rule logic is shown in Figure 4-3. Each of the decision rules are shown for categorizing a tank as safe, conditionally safe, or unsafe. Note that the decision rules require a statistical demonstration that the decision criteria are met. Spatial, sampling, and analytical uncertainties must be considered to confidentiy demonstrate that a tank is either safe or conditionally safe.

Figure 4-2. Ferrocyanide DQO Decision Logic.

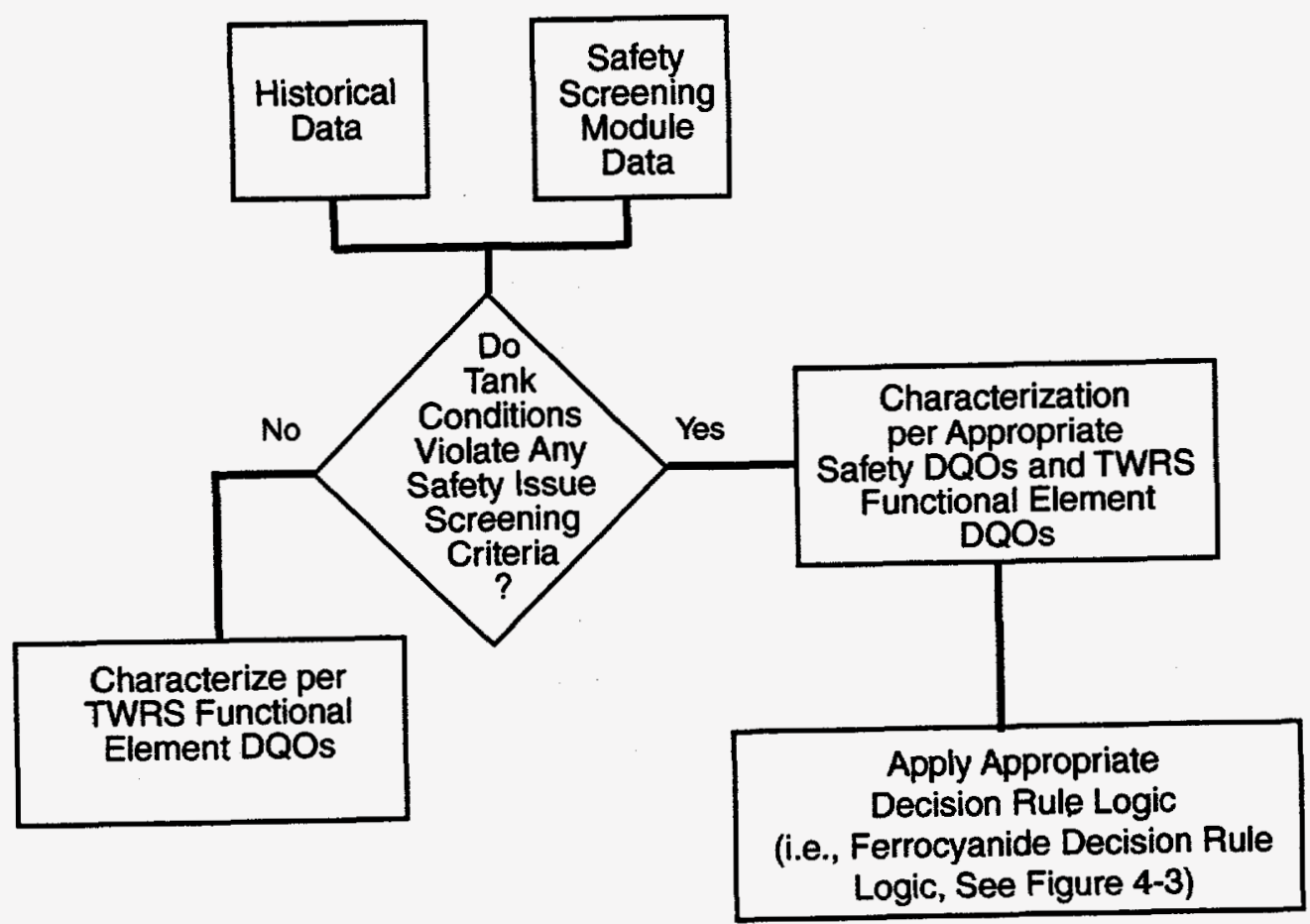

$\$ 9311061.6$ 
WHC-SD-WM-DQO-007 Rev. 0

Figure 4-3. Ferrocyanide DQO Decision Rule Logic.

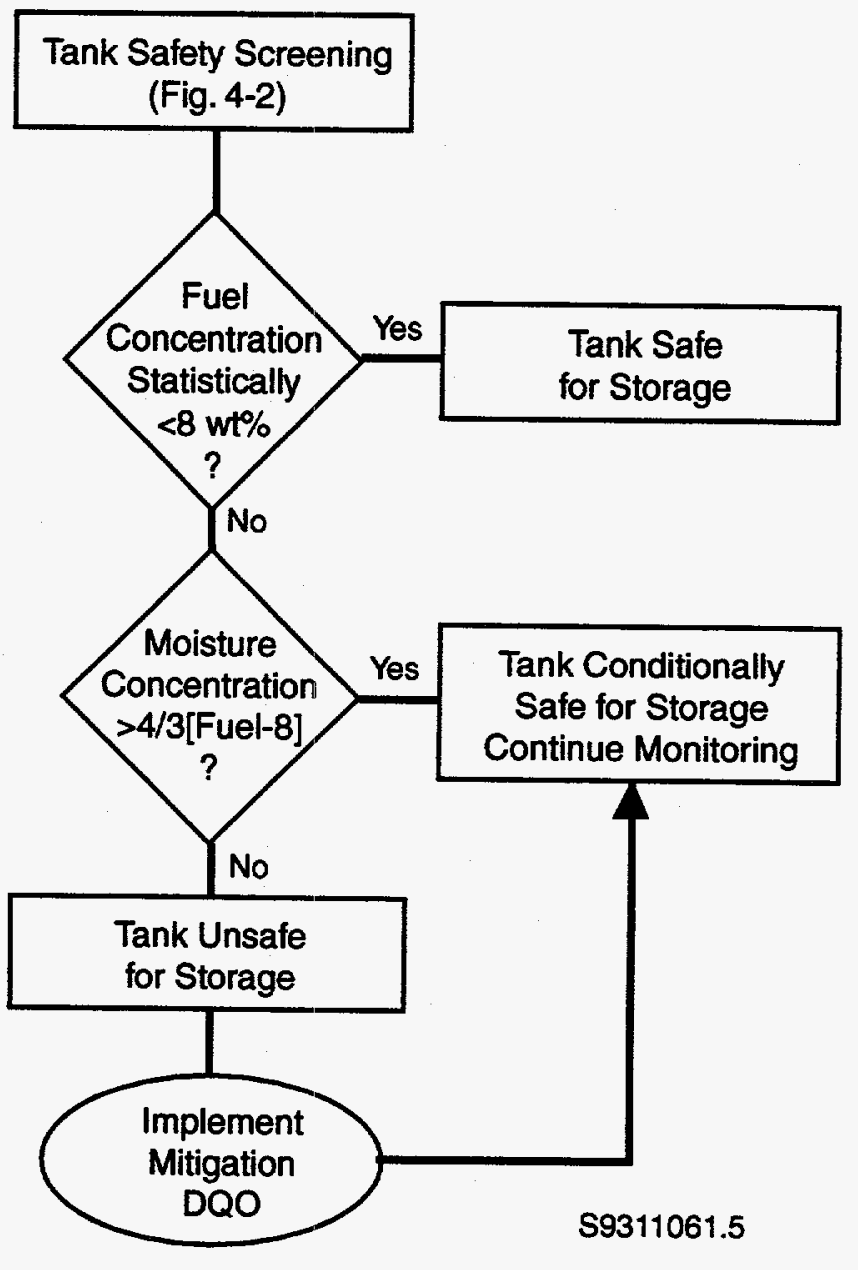


WHC-SD-WM-DQO-007 Rev. 0

\subsection{ERROR TOLERANCES ASSOCIATED WITH MEASUREMENTS}

Error tolerances for the decisions identified in this report represent a balance between the need for precise analytical results and the impact of making an incorrect decision based on the sample results. There is no universal model for determining decision error tolerances; therefore, tolerances are often based on specific assumptions, prior knowledge, and/or expert opinion. The basis for the ferrocyanide decision error tolerances is summarized in this section. A description of discomfort curves (EPA 1993), a pictorial method of presenting the specified decision error tolerances, is also provided in this section.

\subsection{DESCRIPTION OF DISCONFORT CURVES}

A discomfort curve is a way to visually display the acceptable probability of making a decision error. The theory behind these curves is based on statistical hypothesis testing, in which the data are used to decide between one condition of the environment (the null hypothesis, $H_{0}$ ) and an alternative condition (the alternative hypothesis, $H_{9}$ ). The null hypothes is is assumed to be true in the absence of strong evidence to the contrary. A decision error occurs when the decision makers are led to believe in one hypothesis when the other is true.

There are two types of decision errors that must be considered. The first type of decision error occurs when the decision makers conclude, based on the data, that $\mathrm{H}_{1}$ is true when, in fact, $\mathrm{H}_{0}$ is true. This error is sometimes referred to as a false positive, or a Type I, error. The second error occurs when the decision makers conclude, based on available data, that $H_{0}$ is true when, in fact, $H_{1}$ is true. This error is sometimes referred to as false negative, or Type II, error.

The desired probabilities of making both types of decision errors are represented in a discomfort curve. The curve is produced by first determining the possible range of the parameter of interest and setting that to be the bottom axis of the curve. Next, a decision threshold $\left(T_{0}\right)$ is set at the level where action will be required. For example, for the decision that the fuel concentration in a quarter segment is greater than $8 \mathrm{wt} \%$, the bottom axis would represent the range of possible fuel concentrations, and the decision threshold would be 8 wt\% for the discomfort curve.

To develop the discomfort curve, it is necessary to define the acceptable probability of making an incorrect decision if the true value of the parameter of interest is a particular value on the bottom axis. The probability of making an incorrect decision defines the vertical axis of the discomfort curve. For fuel concentration in a quarter segment, the desired probability was defined to be $20 \%$ at the decision threshold ( $8 \mathrm{wt} \%$ fuel). That is, if the true fuel concentration in a quarter segment is $8 \mathrm{wt} \%$, then it is acceptable to have up to a $20 \%$ chance of deciding that the fuel concentration is less than or equal to 8 wt\% (categorizing the tank as safe). The $20 \%$ is a Type I error rate, or false positive $(\alpha)$. Similarly, desired probabilities were also defined at $5 \%$ and $1 \%$ for fuel concentrations of 12 wt\% and 15 wt\%, respectively. 
For a Type II error rate, or false negative (B), the desired probability was defined as $20 \%$ at 4 wt\% fuel. That is, if the true fuel concentration in a quarter segment is 4 wt\%, then it is acceptable to have up to a $20 \%$ chance of deciding that the fuel concentration is greater than 8 wt\% (categorizing the tank as conditionally safe, or unsafe).

\subsection{SAFE VERSUS CONDITIONALLY SAFE OR UNSAFE DECISION RULE}

In Section 4.2, the decision rule was stated as the following: If the fuel concentration for all quarter segment sludge layers is less than 8 wt\% $\mathrm{Na}_{2} \mathrm{NiFe}(\mathrm{CN})_{6}$ (zero free water) on an energy equivalent basis, then the tank is categorized as safe. Otherwise, the tank is categorized as either conditionally safe or unsafe. This decision rule corresponds to a null hypothesis, $H_{0}$, and alternative hypothesis, $H_{1}$, as follows:

$\mathrm{H}_{0}$ : Fuel in quarter segment $(\mu)>8 \%$ wt\% (zero free water) as $\mathrm{Na}_{2} \mathrm{NiFe}(\mathrm{CN})_{6}$ (conditionally safe or unsafe]

$H_{1}$ : Fuel in quarter segment $(\mu) \leq 8 w t \%$ (safe).

Note that the burden of proof is on trying to show that the tank is safe; i.e., $H_{0}$ is assumed true unless sufficient evidence exists to confidently conclude $\mathrm{H}_{4}$ is true. The desired discomfort curve for this decision rule is illustrated in Figure 5-1 and represents the following threshold and error tolerance specifications:

$$
\begin{aligned}
& \text { Decision Threshold }\left(\mathrm{T}_{0}\right)=8 \text { wt\% (zero free water) as } \mathrm{Na}_{2} \mathrm{NiFe}(\mathrm{CN})_{6} \\
& \text { Type I Error Rate }\left(\alpha_{1}\right) \leq 20 \% \text { (at } \mu=8 \% \text { wt\% fuel) } \\
& \text { Type I Error Rate }\left(\alpha_{2}\right) \leq 5 \% \text { (at } \mu=12 \% \text { wt\% fuel) } \\
& \text { Type I Error Rate }\left(\alpha_{3}\right) \leq 1 \% \text { (at } \mu=15 \% \text { wt\% fuel) } \\
& \text { Type II Error Rate }(\beta) \leq 20 \% \text { (at } \mu=4 \% \text { wt\% fuel). }
\end{aligned}
$$

\section{Rationale for Decision Error Tolerances}

When determining the acceptable probability of making an incorrect decision, the consequences of that decision error must be assessed. It is tempting to ignore statistical uncertainties and state that whenever the fuel

concentration is greater than 8 wt\%, it will be concluded with $100 \%$ confidence that the tank is either conditionally safe or unsafe, regardless of whether or not the true value is close to $8 \mathrm{wt} \%$. However, statistical uncertainties cannot be ignored. Thus, acceptable probabilities of making decision errors must be specified considering the consequences of those decision errors.

The consequences of miscategorizing a tank with slightly greater than $8 \mathrm{wt} \%$ fuel (for any one quarter segment) are very small because of the large conservatism factored into the 8 wt\% fuel decision criterion. The 8 wt\% fuel criterion was based on conservative theoretical calculations that ignored the kinetic factors in a propagating reaction. Experiments on waste simulants (Epstein et a1. 1994) and theoretical calculations incorporating kinetic factors (Postma et al. 1994) have shown that almost twice this fuel concentration $(-15$ wt\%) is necessary to sustain a propagating reaction. 
Figure 5-1. Discomfort Curve for Ferrocyanide Concentration Used to Show Decision Error Tolerance

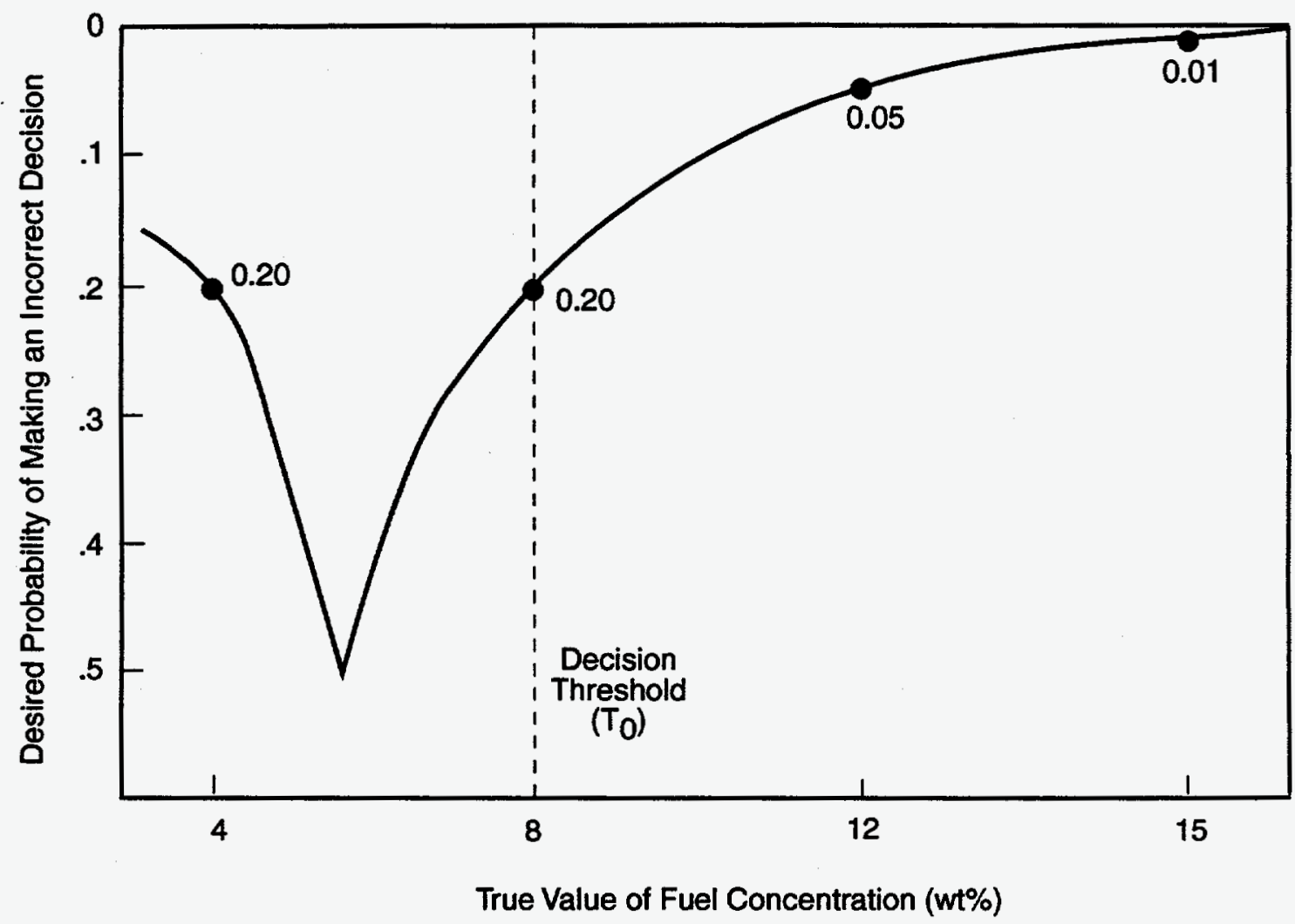

$\$ 9311061.4$

If a high error tolerance (e.g., 95\% or 99\%) were specified for the 8 wt\% fuel decision rule, then large conservatism would be multiplied by more conservatism, resulting in extremely stringent and costly sampling requirements that do not reflect the actual ferrocyanide risk. Therefore, it was deemed acceptable to have a $20 \%$ probability of concluding that a tank is safe if the true fuel concentration is $8 \mathrm{wt}$. However, the ferrocyanide risk (i.e., consequence of miscategorizing a tank) increases as the fuel value increases. To reflect this, the acceptable probability decreases as the fuel value increases. A $1 \%$ chance of categorizing a tank as safe is required if the true fuel concentration is $15 \mathrm{wt} \%$, and a $5 \%$ chance of categorizing a tank as safe is required if the true fuel concentration is $12 \mathrm{wt} \%$. These probabilities provide adequate protection given that other data will be available to corroborate, or refute, the appropriateness of the decision, and that continued prudent monitoring of the tanks is planned.

Although acceptable error tolerances have been defined for 8,12 , and 15 wt\% fuel, much lower fuel values are anticipated. There exists a strong precedence for expecting fuel concentrations to be far below the 8 wt\% criterion, because of waste aging (Babad et a1. 1993). Analyses from tanks 241-C-109 and 241-C-112, two of the four Ferrocyanide Watch List tanks expected to have the highest concentration (up to $26 \mathrm{wt} \%$ ), revealed concentrations that were about a factor of 10 less (1 to 2.9 wt\%) than 
predicted from the original flowsheets (Jeppson and Wong 1993, Simpson et al. 1993a, 1993b, Sloat 1954).

The consequence of miscategorizing a tank as conditionally safe or unsafe, when it is in fact safe, is primarily driven by the need for prudent use of resources and the desire to avoid unnecessary safety concerns. Therefore, it was deemed acceptable to have up to a $20 \%$ chance of concluding that a tank is unsafe or conditionally safe when the true fuel value is 4 wt\%. However, ferrocyanide concentrations less than 4 wt\% are expected for a11 of the remaining tanks.

Note that these desired probabilities of decision errors are used to define the sampling requirements. Once the sampling requirements are defined, the achieved decision error probabilities may be improved (see Section 6.0)

\subsection{CONDITIONALLY SAFE VERSUS UNSAFE DECISION RULE}

The decision rule to distinguish between conditionally safe and unsafe was described in Section 4.3. That is, if moisture in a quarter segment layer is greater than or equal to $4 / 3$ (wt\% fuel - 8 wt\%), then the tank can be categorized as conditionally safe; otherwise it must be categorized as unsafe. This decision rule corresponds to a null hypothesis, $\mathrm{H}_{0}$, and an alternative hypothesis, $H_{1}$, as follows:

$$
\begin{array}{lll}
H_{0}: & \text { Moisture }<4 / 3 \quad \text { (wt\% fuel }-8 w t \%) & \text { (unsafe) } \\
H_{1}: & \text { Moisture } \geq 4 / 3 \quad \text { [wt f fuel }-8 w t \%] & \text { (conditional7y Safe). }
\end{array}
$$

Again, the burden of proof is on trying to show that the tank is conditionally safe; $H_{0}$ (unsafe) is assumed unless sufficient data are available to confidentiy conclude $H_{1}$ is true. In order to make these hypotheses more compatible with the discomfort curve terminology, the equations can be algebraically manipulated to the following statements:

$$
\begin{aligned}
& H_{0}: \text { Fuel }-3 / 4 \text { (wt\% moisture) }>8 \text { wt\% or } H_{0}: \quad K>8 \text { wt\% } \\
& H_{1}: \text { Fue1 - } 3 / 4 \text { (wt\% moisture) } \leq 8 \text { wt\% or } H_{1}: \quad K \leq 8 \text { wt\% }
\end{aligned}
$$

Where $K=$ wt\% fuel $-3 / 4$ (wt\% moisture).

Figure 4-1 in Section 4.3 illustrates this decision rule. This same diagram was used to specify the decision error tolerances shown in Figure 5-2. For example, if the true fuel concentration is 26 wt\% and the true moisture content is $20 \mathrm{wt} \%(K=11)$, the tank should be categorized as unsafe. For this case, a $5 \%$ chance of categorizing the tank as conditionally safe is required. The discomfort curve shown in Figure 5-3 was constructed by using $K$ on the horizontal axis. The corresponding error tolerance specifications are:

$$
\text { Decision Threshold }\left(T_{0}\right): K=8 \text { wt\% }
$$

Type I Error Rate $\left(\alpha_{1}\right)=10 \%$ at $K=8$ wt\%; fuel $=26$ wt\% and mo isture $=24$ wt\% Type I Error Rate $\left(\alpha_{2}\right)=5 \%$ at $K=11$ wt\%; fuel $=26$ wt\% and moisture $=20$ wt\% Type I Error Rate $\left(\alpha_{3}\right)=1 \%$ at $K=17$ wt\%; fuel $=26$ wt\% and mo isture $=12$ wt\% Type II Error Rate $\left(\beta_{1}\right)=5 \%$ at $K=-3$ wt\%; fuel $=15$ wt\% and mo isture $=24$ wt $\%$ Type II Error Rate $\left(\beta_{2}\right)=1 \%$ at $K=-10 \mathrm{wt} \%$; fuel $=8$ wt\% and moisture $=24$ wt\% 
Figure 5-2. Moisture Diagram.

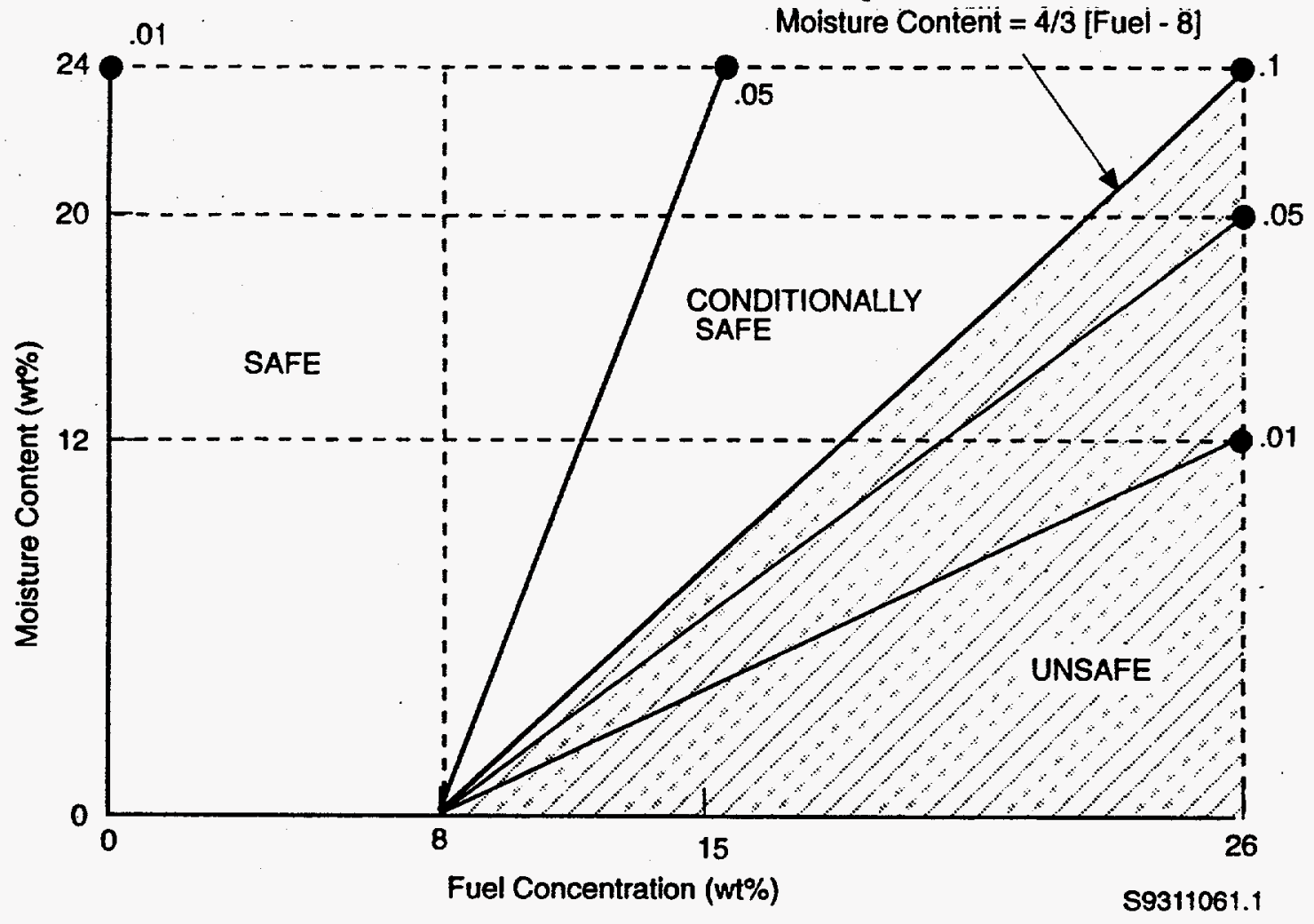

Figure 5-3. Discomfort Curve.

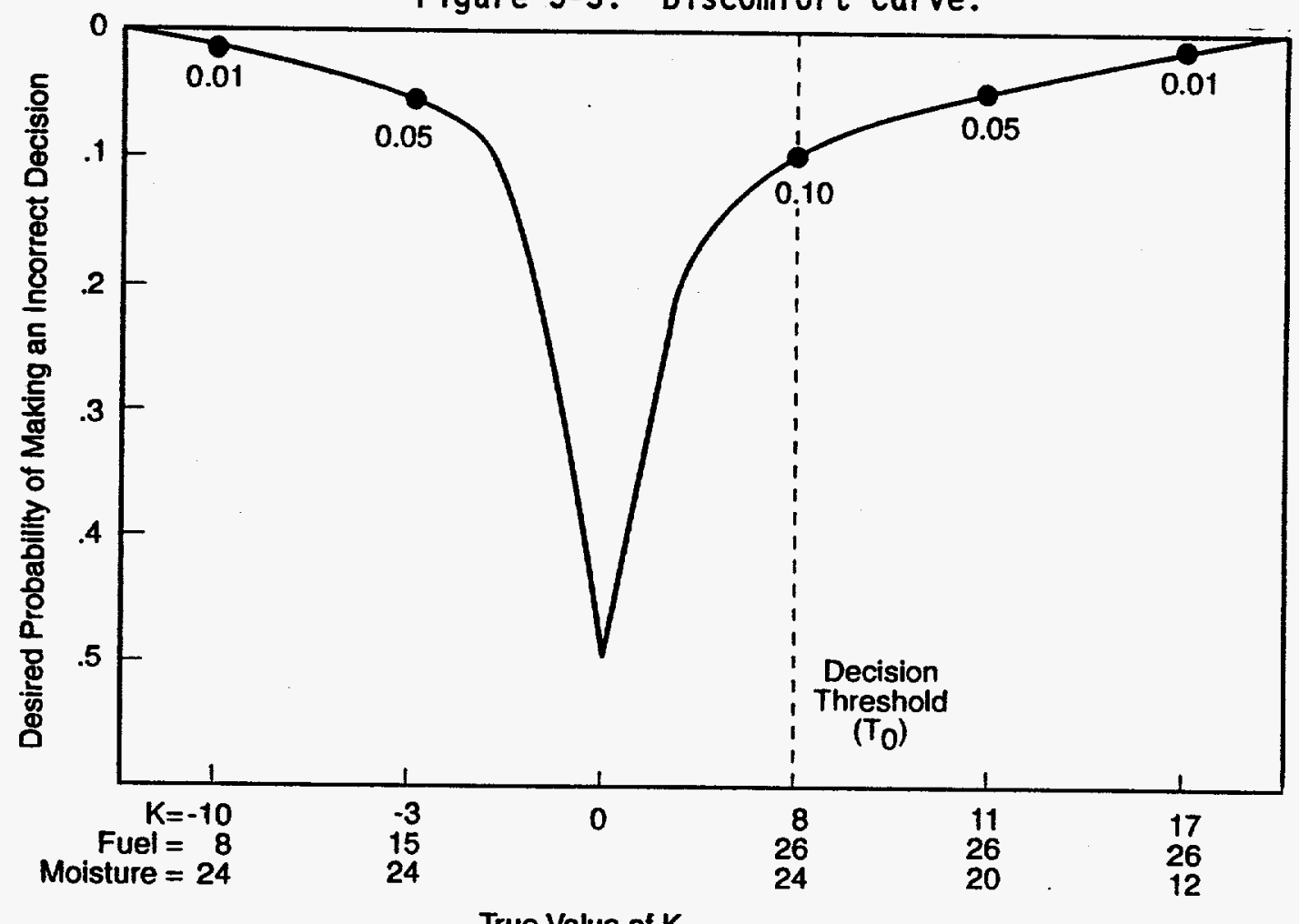

( $\mathrm{K}=$ Fuel - $3 / 4$ Moisture Content) 


\section{Rationale for Decision Error Tolerances}

The justification for the desired decision error probabilities for the moisture-based decision rule is similar to the argument presented for the ferrocyanide-based decision rule. There is significant conservatism inherent in the moisture criteria. For example, at 26 wt\% fuel, the corresponding moisture criterion is $24 \mathrm{wt} \%$ (Postma et al. 1994). However, experiments have shown that 12 wt\% moisture will prevent propagating reactions at 26 wt\% fuel (Jeppson and Wong 1993). Thus, a safety factor of two is built into the criterion. Given this conservatism, a $10 \%$ chance of categorizing a tank as conditionally safe when the fuel concentration is $26 . \mathrm{wt} \%$ and the moisture is 24 wt\% was deemed acceptable.

As the ratio of moisture to fuel decreases, the consequence of making an incorrect decision increases. Because experiments have shown that 12 wt\% moisture will prevent propagating reactions at 26 wt\% fuel, a $1 \%$ chance of concluding that a tank was conditionally safe if $K=17$ (fuel $=26$ wt\%, moisture $=12$ wt\%) was deemed acceptable. Likewise, a $5 \%$ chance of concluding that a tank was conditionally safe if $K=11$ (fuel $=26 \mathrm{wt} \%$, moisture $=$ 20 wt\%) was deemed acceptable.

Adequate protection is also desired against categorizing a tank as unsafe, when in fact it is conditionally safe. Unnecessary expense and concern would be the result of this miscategorization. In the extreme case that the fuel concentration was slightly above $8 \mathrm{wt} \%$ and moisture content was $24 \mathrm{wt} \%$, a $1 \%$ chance of categorizing the tank as unsafe is required. If the fuel concentration was $15 \mathrm{wt} \%$ and the moisture content was $24 \mathrm{wt} \%$, a $5 \%$ chance of categorizing the tank as unsafe is required. 


\subsection{OPTIMAL SAMPLING DESIGN}

Optimal sampling requirements are determined by combining the information illustrated in the discomfort curves with estimates of uncertainty that incorporate all relevant sources of variability. Sources of variability that are applicable to the Ferrocyanide Safety Issue include tank-to-tank variability, core-to-core variability, quarter segment-to-quarter segment variability, sample preparation variability, and analytical variability. In this section, the factors that affect sample requirements will be discussed, the estimates of uncertainty for the Ferrocyanide Safety Issue will be presented, and requirements for the number of core samples will be provided.

\subsection{FACTORS AFFECTING SAMPLING REQUIREMENTS}

The primary characterization method for the Ferrocyanide Watch List tanks is core sampling ${ }^{8}$. However, in the future, neutron diffusion, near-infrared technology, or some other technique may become primary sources for moisture measurements. Physical constraints, inherent sample variabilities, and decision error tolerances directly affect the number of cores required for adequate characterization. Assumptions on statistical distribution are also key in determining sampling requirements. Non-central t-distribution (see Appendix B) was assumed for all sample requirement calculations. Previous core sample results from two ferrocyanide tanks suggest this is an appropriate assumption. Estimates of uncertainty, based on core sampling results, are provided in Section 6.1 .1 .

\subsubsection{Estimates of Uncertainty from Prior Information}

The information illustrated in the discomfort curves is an important factor affecting sample requirements. It is the pertinent information regarding the tolerance to making Type I and Type II errors, and also relates to the estimates of uncertainty. If the uncertainty is large and the consequences of making an incorrect decision are significant, more samples would be required. Consequently, estimates of uncertainty are required to develop an optimal sampling scheme (Heasler et a1. 1993a).

Estimates of uncertainty, called relative standard deviations (RSDs), were obtained (where possible) using analyses of 5 core samples from Ferrocyanide Watch List tanks 241-C-109 and 241-C-112. The spatial, sampling, and analytical variations observed are assumed to be representative of most Ferrocyanide Watch List tanks. Current available data include ferrocyanide concentrations on quarter segments, moisture content on quarter segments, and nickel concentrations on core composites. Analytical uncertainties, calculated from this data, are presented in Table 6-1.

\footnotetext{
${ }^{8}$ Core sampling data cannot, and will not, be used to address temperature and "hot-spot" concerns, although strontium and cesium measurements from core samples are used to address these issues.
} 
Table 6-1. Calculated Analytical Uncertainties Using Data From Tanks 241-C-109 and 241-C-112.

\begin{tabular}{|c|l|c|c|}
\hline Analyte & \multicolumn{1}{|c|}{ Analytical Method } & Sample & $\begin{array}{c}\text { Calculated } \\
\text { Analytical } \\
\text { Uncertainty }\end{array}$ \\
\hline \hline Nickel & $\begin{array}{l}\text { Inductively Coupled Plasma-Acid } \\
\text { Digestion and Fusion }\end{array}$ & $\begin{array}{c}\text { Quarter } \\
\text { Segment }\end{array}$ & $5 \%^{1}$ \\
\hline Total Fuel & $\begin{array}{l}\text { Differential Scanning } \\
\text { Calorimetry/Adiabatic Calorimetry }\end{array}$ & $\begin{array}{l}\text { Quarter } \\
\text { Segment }\end{array}$ & $3 \%^{2}$ \\
\hline Moisture & Thermogravimetric Analysis & $\begin{array}{c}\text { Core } \\
\text { Composite }\end{array}$ & $5 \%$ \\
\hline
\end{tabular}

1 The analytical uncertainty for nickel contains uncertainty from sample preparation and analytical variability.

2 The analytical uncertainty for total cyanide contains uncertainty from sample preparation and analytical variability (excluding variations from sample extrusion and homogenization).

Analysis of variance techniques was used to estimate the variance for each of the sources of variability (or variance components). The results for ferrocyanide and nickel concentrations indicated that the tank-to-tank variability is not significantly different from zero. The core-to-core RSDs and the analytical RSDs showed good agreement for ferrocyanide and nickel concentrations. The overall estimate of uncertainty (RSD) is approximately $22 \%$ of the mean for both ferrocyanide and nickel concentrations. This estimate accounts for both core-to-core and analytical uncertainty. An independent review of the $22 \%$ RSD calculation is presented in Appendix D.

The tank-to-tank variability for moisture content was significantly different from zero, although this estimate was based on a small number of data points. The overall estimate of uncertainty (RSD) is approximately $12 \%$ of the mean for moisture. This estimate accounts for tank-to-tank, core-to-core, and analytical uncertainty. Therefore, because tank-to-tank variations are included, the estimate is a conservative value for the RSD of interest. However, this value is not the appropriate uncertainty estimate to use for the decision rule that gives moisture content as a function of ferrocyanide concentration. For that decision rule, a combined estimate of uncertainty was used that incorporates both ferrocyanide and moisture variations. The estimate of RSD for the conditionally safe versus unsafe decision rule is $22 \%$, dominated by the ferrocyanide concentration variability.

Core sample data from two other SSTs (tanks 241-B-110 and 241-U-110) have been analyzed and are sufficient for estimation of spatial, sampling, and analytical uncertainties (Heasler et al. 1993b). The statistical analysis of these tanks indicated that the overall RSD could range from $10 \%$ to $100 \%$. The RSDs of this report are very specific because they were calculated using only cyanide, nickel, and moisture data from two Ferrocyanide Watch List tanks and were based on five cores. The RSD estimate will be updated as additional 
WHC-SD-WM-DQO-007 Rev. 0

samples become available. Section 6.2 addresses the sensitivities of estimated RSD's and the number of core samples required.

\subsubsection{Number of Cores Required}

The number of cores required to meet the specified decision rules can be calculated using the $22 \%$ RSD and information from the discomfort curves shown in Sections 5.2 and 5.3. A formula for calculating the required number of core samples is provided in Appendix B. TWO core samples are required for the safe versus conditionally safe or unsafe decision rule and the conditionally safe versus unsafe decision rule.

\subsubsection{Achievable Probabilities of Making Incorrect Decisions}

Assuming that two cores will be taken from a Ferrocyanide Watch List tank and the overall estimate of variability (RSD) is $22 \%$, the achievable probabilities of making incorrect decisions can be estimated. If the discomfort curve represents the desired probabilities for decision error, these calculations represent the actual probabilities for decision error under these assumptions.

For the safe versus conditionally safe or unsafe decision rule, the estimate of standard deviation is calculated by assuming that the standard deviation for all possible fuel values is constant, and that the RSD is $22 \%$ at 8 wt\% fuel. The standard deviation for the mean fuel concentration is calculated by taking the RSD times eight divided by the square root of two. For this decision rule, the standard deviation for the mean is estimated to be 1.2445 wt\%. This value was used to calculate all probabilities. At 8 wt\% fuel, the achievable probability for decision error with two cores is 0.20 ; at 4 wt\% fuel, the achievable probability for decision error is 0.0588 ; at 12 wt\% fuel, the achievable probability for decision error is 0.0001 , and at 15 wt\% fuel the achievable probability for decision error is less than 0.0001 . Except for the 0.20 probability for decision error, which was fixed, all other achievable probabilities are well below the desired values. Table 6-2 summarizes these values along with the desired decision error probabilities.

Table 6-2. Achievable Probabilities for Decision Error for the Safe Versus Conditionally Safe or Unsafe Decision Rule.

\begin{tabular}{|c|c|c|}
\hline $\begin{array}{c}\text { Fuel as } \\
\mathrm{Na}_{2} \mathrm{NiFe}(\mathrm{CN})_{6} \\
(w t \%)\end{array}$ & $\begin{array}{c}\text { Desired Probability } \\
\text { for Decision Error }\end{array}$ & $\begin{array}{c}\text { Achievable Probability } \\
\text { for Decision Error at } \\
\text { RSD }=22 \%\end{array}$ \\
\hline \hline 4 & 0.20 & 0.0588 \\
\hline 8 & 0.20 & 0.20 \\
\hline 12 & 0.05 & 0.0001 \\
\hline 15 & 0.01 & $<0.0001$ \\
\hline
\end{tabular}

For the conditionally safe versus unsafe decision rule, the assumption of. constant standard deviation is also made. At $K=8 \mathrm{wt} \%$, the achievable probability for decision error with two cores is 0.10 ; at $K=-3$ wt\%, the achievable probability for decision error is 0.0063 ; at $K=-10$ wt\%, the 
achievable probability for decision error is less than 0.0001 ; at $K=11$ wt\%, the achievable probability for decision error is 0.0001 ; and at $K=17 \mathrm{wt} \%$, the achievable probability for decision error is less than 0.0001 . Except for the 0.10 probability for decision error, which is fixed, all other achievable probabilities are well below the specified values. Table 6-3 summarizes these values along with the desired decision error probabilities.

Table 6-3. Achievable Probabilities for Decision Error for the Conditionally Safe Versus Unsafe Decision Rule.

\begin{tabular}{|c|c|c|c|c|}
\hline $\begin{array}{c}\text { Fuel as } \\
\mathrm{Na}_{2} \mathrm{NiFe}(\mathrm{CN})_{6} \\
\text { (wt\%) }\end{array}$ & $\begin{array}{c}\text { Moisture } \\
\text { (wt\%) }\end{array}$ & $\begin{array}{c}\mathrm{K} \\
\text { (wt\%) }\end{array}$ & $\begin{array}{c}\text { Desired } \\
\text { Probability for } \\
\text { Decision Error }\end{array}$ & $\begin{array}{c}\text { Achievable Probability } \\
\text { for Decision Error at } \\
\text { RSD }=22 \%\end{array}$ \\
\hline \hline 8 & 24 & -10 & 0.01 & $<0.0001$ \\
\hline 15 & 24 & -3 & 0.05 & 0.0063 \\
\hline 26 & 24 & 8 & 0.10 & 0.10 \\
\hline 26 & 20 & 11 & 0.05 & 0.0007 \\
\hline 26 & 12 & 17 & 0.01 & $<0.0001$ \\
\hline
\end{tabular}

\subsection{SENSITIVITIES OF NUMBER OF CORES AND RSD CALCULATIONS}

Sample size results presented thus far are based on certain assumptions (the most notable being a RSD of 22\%); therefore, it is reasonable to ask what would happen if some assumptions were wrong. Sensitivity calculations have been performed to assess the effect of RSD (spacial and analytical variability), true fuel concentration, and number of core samples, on the ability to meet the specified error tolerances. Summaries of the sensitivity calculations are presented in Appendix $C$.

For the safe versus conditionally safe or unsafe decision rule and with two core samples, the RSD can be as high as 33\% and still meet the desired decision error tolerances. At an RSD of 33\%, the standard deviation of the mean at $8 \mathrm{wt} \%$ fuel is $2.4890 \mathrm{wt} \%$. At $8 \mathrm{wt} \%$ fuel, the achievable probability for decision error with 2 cores is 0.20 ; at 4 wt\% fuel, the achievable probability is 0.2047 ; at 12 wt\% fuel, the achievable probability is 0.0032 ; and at 15 wt\% fuel, it is less than 0.0001 . The limiting factor is the decision error probability at 4 wt\% fuel. For three core samples, an RSD of up to $46 \%$ can be tolerated, and for four core samples an RSD up to $55 \%$ can be tolerated.

The effect of tightening the Type I error at 8 wt\% from $20 \%$ to $5 \%$ (i.e., decreasing the chance from $20 \%$ to $5 \%$ of categorizing a tank with a fuel content greater than 8 wt\% as safe) was examined. The benefits from tightening the requirements at 8 wt\% are very smal1. At fuel concentrations greater than $10 \mathrm{wt} \%$, there is no significant decrease in the probability of making an incorrect decision (Type I error). However, at fuel concentrations less than 6 wt\% there is a dramatic increase in the probability of making an incorrect decision (Type II error). For example, at a true fuel concentration of $4 \mathrm{wt} \%$, one is 10 times more likely to categorize a safe tank as 
conditionally safe or unsafe. As a result, many more tanks that are safe would be categorized as conditionally safe or unsafe. To decrease the probability of Type II errors to the same levels as before, the number of core samples required would increase to four.

In an effort to determine how large the RSD can be and still achieve the desired probabilities outlined in the discomfort curves, the limiting RSD was calculated for various core sampling scenarios. These limiting RSDs were determined assuming a normal distribution and a constant standard deviation equivalent to the RSD at $8 \mathrm{wt} \%$. If only two core samples are obtained, an RSD up to $33 \%$ can be tolerated and still meet the desired probabilities of decision errors. Similarly, if three cores are obtained, an RSD of up to $46 \%$ can be tolerated.

An evaluation was also performed to determine how large an RSD could be tolerated and still assure that the decision error probabilities affecting safety were maintained. If categorizing a tank with a fuel content $>8$ wt\% is the only concern (i.e., there is no concern about incorrectly categorizing a safe tank as conditionally safe or unsafe), then an RSD of up to $73 \%$ could be accepted and still meet the specified error tolerances.

In general, because tanks are assumed conditionally safe or unsafe until proven otherwise, the probabilities of making a Type I decision error (i.e., categorizing a conditionally safe or unsafe tank as safe) are very smal1. This probability is little affected by increasing the number of core samples for high fuel concentrations. However, the probability of concluding that a tank is conditionally safe or unsafe when it is really safe (Type II decision errors) is affected by the number of cores taken, particularly if a Type I decision error $\leq 5 \%$ is required.

For the conditionally safe versus unsafe decision rule and with two core samples, the RSD can be as high as 30\% and still achieve the desired decision error tolerances. At an RSD of $30 \%$, the standard deviation of the mean at $K=8 w t \%$ is $3.7335 w t \%$. At $K=8 w t \%$, the achievable probability for decision error with two cores is 0.10 ; at $K=-3$ wt\%, the achievable probability is 0.045 ; at $K=-10$ wt\%, the achievable probability is 0.0011 ; at $K=11$ wt\%, it is 0.0040 ; and at $K=17$ wt\%, the achievable probability is less than 0.0001 . Consequently, the RSD can be as high as $30 \%$, and the desired decision error tolerances will be met (the limiting factor is the decision error probability at $K=-3 w t \%)$.

Analytical uncertainty affects the RSD and ultimately the number of cores required to adequately characterize a tank. It may be difficult to consistently maintain the analytical uncertainties seen in the data from tanks 241-C-109 and 241-C-112 (Table 6-1). Therefore, the required analytical uncertainties were relaxed to $10 \%$ for the primary and secondary data requirements. This increased the assumed RSD for ferrocyanide tanks to $24 \%$.

It should be noted that the required analytical uncertainties specified in Tables S-1 and 3-1 are only necessary near the decision threshold values. If a measured value is less than $25 \%$ of the decision threshold, then the specified analytical uncertainty is not required. If a decision threshold is 
not specified, then values less than 10 times the detection limit do not require the specified analytical uncertainty. This is allowable because as the measured values decrease, much higher analytical uncertainties can be accepted and still meet the decision error tolerances. 


\subsection{CONCLUSIONS}

A logical, defensible approach to defining core sampling requirements was developed and documented, while recognizing inherent spatial, sampling, and analytical uncertainties. Two key decision rules were defined for categorizing a Ferrocyanide Watch List tank as safe, conditionally safe, or unsafe for interim storage. Uncertainties also have been addressed and managed to acceptable levels. Finally, this process provided a mechanism for communicating the integral relationships between sampling requirements and desired levels of protection against making incorrect decisions.

\subsection{FINDINGS}

The DQO process has been applied to the Ferrocyanide Safety Issue to determine the data requirements and to develop an appropriate sampling scheme. Sampling requirements were defined to ensure adequate protection against making incorrect decisions.

The major findings of this process are as follows:

- Two core samples are required to categorize each Ferrocyanide Watch List tank as safe, conditionally safe, or unsafe.

- Analytical measurements associated with the safety criteria parameters (i.e., primary data requirements) for Ferrocyanide Watch List tanks must be applied to quarter segments for sludge layers and half segments for saltcake layers.

- Key analytes for the decision rules are fuel concentration (determined through energetics measurements) and moisture content (determined through thermogravimetric analysis). Secondary measurements include total cyanide, nicke1, cesium-137, strontium-90, and TOC.

- Desired decision error tolerances are still achieved with two core samples even if the fuel RSD increases from the current best estimate of $22 \%$ up to $33 \%$.

- Relaxing the required analytical uncertainties to $10 \%$ results in an overall RSD of $24 \%$.

\subsection{RECOMMENDATIONS}

Where possible, sampling locations should be chosen to increase the likelihood for obtaining samples that represent the true spatial variations within a tank (e.g., opposite sides or side-center for two cores, side-center-side for three cores).

RSD estimates shall be updated as more data become available. Using data from ferrocyanide tanks $241-C-109$ and $241-C-112$, an RSD of $22 \%$ for fuel and $12 \%$ for 
moisture have been used to develop the sampling requirements. If revised RSDs vary significantly from these assumed values, the required number of cores may need to be modified.

When analytical results for each Ferrocyanide Watch List tank are received, a statistical evaluation will be conducted (to assess the design performance by comparing desired error tolerances to the achieved values) to determine the confidence with which one can conclude that a tank is safe or conditionally safe. 


\subsection{REFERENCES}

Babad, H., J. E. Meacham, B. C. Simpson, and R. J. Cash, 1993, The Role of Aging in Resolving the Ferrocyanide Safety Issue, WHC-EP-0599, Westinghouse Hanford Company, Richland, Washington.

Babad, H., and D. A. Turner, 1993, Interim Criteria For Organic Watch List Tanks at the Hanford Site, WHC-EP-0681, Westinghouse Hanford Company, Richland, Washington.

Babad, H., and K. S. Redus, 1994, Tank Safety Screening Data Quality Objectives, WHC-SD-WM-DQ0-004, Rev. 0, Westinghouse Hanford Company, Richland, Washington.

Bell, K.E., 1994, Tank Waste Remediation System Tank Waste Analysis Plan, WHC-SD-WM-PLN-077, Rev. 0, Westinghouse Hanford Company; Richland, Washington.

Borsheim, G. L., and B. C. Simpson, 1991, An Assessment of the Inventories of the Ferrocyanide Watch List Tanks, WHC-SD-WM-ER-133, Rev. 0, Westinghouse Hanford Company, Richland, Washington.

Borsheim, G. L., J. E. Meacham, R. J. Cash, and B. C. Simpson, 1993, Ferrocyanide Safety Program: Rationale for Removing Six Tanks From the Safety Watch List, WHC-MR-0429, Westinghouse Hanford Company, Richland, Washington.

Burger, L. L., and R. D. Scheele, 1988, Interim Report, Cyanide Safety Studies, PNL-7175, Pacific Northwest Laboratory, Richland, Washington.

Burger, L. L., 1989, Complexant Stability Investigation, Task 1 - Ferrocyanide Solids, PNL-5441, Pacific Northwest Laboratory, Richland, Washington.

Deaton, D. E., 1990, Unusual Occurrence - Unreviewed Safety Questions Regarding Tanks Containing Ferrocyanide, WHC-90-B003-R1

(Update 10-22-90), Westinghouse Hanford Company, Richland, Washington.

DOE, 1986, Safety of Nuclear Facilities, DOE Order 5480.5, U.S. Department of Energy, Washington, D.C.

DOE, 1991, Unreviewed Safety Questions, DOE Order 5480.21, U.S. Department of Energy, Washington, D.C.

EPA, 1987, Data Quality Objectives for Remedial Response Activities - Example Scenario: RI/FS Activities at a Site with Contaminated Soils and Ground Water, PB90-272634, U.S. Environmental Protection Agency, Washington D.C.

EPA, 1993, Guidance for P7anning for Data Collection in Support of Environmental Decision Making Using the Data Quality Objectives Process, EPA QA/G-4 (interim fina7), U.S. Environmental Protection Agency, Washington, D.C. 
Epstein, M., H. K. Fauske, R. J. Cash, and J. E. Meacham, 1994, Conditions for Reaction Propagation in Dried Ferrocyanide/Nitrate-Nitrite Powders, WHC-SD-WM-TI-619, Rev. 0, Westinghouse Hanford Company, Richland, Washington.

Fauske, H. K., 1992, Adiabatic Calorimetry and Reaction Propagation Tests with Synthetic Ferrocyanide Materials Including U Plant 1, U Plant 2, In Farm 1, In Farm 2, and Vendor Procured Sodium Nickel Ferrocyanide, WHC-SD-WM-RPT-054, Rev. 0, Westinghouse Hanford Company, Richland, Washington.

Fowler, K. D., 1994, Action Plan for Response to Abnormal Conditions in Hanford Site Radioactive Waste Tanks Containing Ferrocyanide, WHC-EP-0407, Rev. 2, Westinghouse Hanford Company, Richland, Washington.

Heasler, P. G., C. M. Anderson, and D. B. Baird, 1993a, Generic Tank Characterization Estimation and Sample Size Problems, PNL Letter report, Pacific Northwest Laboratory, Richland, Washington.

Heasler, P. G., C. M. Anderson, D. B. Baird, R. J. Serne, and P. D. Whitney, 1993b, Statistical Evaluation of Core Samples From Hanford Tank B-110, PNL-8745, Pacific Northwest Laboratory, Richland, Washington.

Jeppson, D. W., and J. J. Wong, 1993. Ferrocyanide Waste Simulant Characterization, WHC-EP-0631, Westinghouse Hanford Company, Richland, Washington.

Lilga, M. A., M. R. Lumetta, and G. F. Schiefelbein, 1993, Ferrocyanide Safety Project, Task 3 Aging Studies, FY 1993 Annual Report, PNL-8888, Pacific Northwest Laboratory, Richland, Washington.

Meacham, J. E., R. J. Cash, and G. T. Dukelow, 1993, Quarterly Report on Defense Nuclear Facilities Safety Board Recommendation 90-7 for the Period Ending September 30, 1993, WHC-EP-0474-10, Westinghouse Hanford Company, Richland, Washington.

Neptune, D., E. P. Brantly, M. J. Messner, and D. I. Michael, 1990, "Quantitative Decision Making in Superfund: A Data Quality Objectives Case Study," Hazardous Materials Control 3(3):19-27.

Peach, J. D., 1990, Consequences of Explosion of Hanford's Single-Shell Tanks Are Understated, (GAO Letter B-241479 to C. M. Synar, Chairman of Environment, Energy and National Resources Subcommittee, Committee on Government Operations, House of Representatives, October 10), GAO/RCED-91-34, General Accounting Office, Washington, D.C.

Postma, A. K., J. E. Meacham, R. J. Cash, W. S. Barney, G. L. Borsheim, M. D. Crippen, D. R. Dickinson, D. W. Jeppson, M. Kummerer, J. L. McLaren, C. S. Simons, and B. C. Simpson, 1994, Safety Criteria for Ferrocyanide Watch List Tanks, WHC-EP-0691, Westinghouse Hanford Company, Richl and, Washington. 
Sheridan, T. R., 1994, Closure of the Ferrocyanide Unreviewed Safety Question, (external letter 94-SST-052 to A. L. Trego, Westinghouse Hanford Company, March 4), U.S. Department of Energy-Richland Operations Office, Richland, Washington.

Simpson, B. C., G. L. Borsheim, and L. Jensen, 1993a, Tank Characterization Report: Tank 241-C-109, WHC-EP-0668, Rev. 1, Westinghouse Hanford Company, Richland, Washington.

Simpson, B. C., G. L. Borsheim, and L. Jensen, 1993b, Tank Characterization Data Report: Tank 241-C-112, WHC-EP-0640, Rev. 1, Westinghouse Hanford Company, Richland, Washington.

Sloat, R. J., 1954, In Farm Scavenging Operating Procedure and Control Data, HW-38955, Rev. 1, General Electric Company, Richland, Washington.

Smith, D.A., 1986, Single-Shell Tank Isolation Safety Analysis Report, SD-WM-SAR-006, Rev. 2, Westinghouse Hanford Company, Richland, Washington.

WHC, 1993, Nonreactor Facility Safety Analysis Manual, WHC-CM-4-46, Westinghouse Hanford Company, Richland, Washington. 
WHC-SD-WM-DQ0-007 Rev. 0

This page intentionally left blank. 
WHC-SD-WM-DQO-007 Rev. 0

APPENDIX A

DESCRIPTION OF DQO PROCESS 
WHC-SD-WM-DQO-007 Rev. 0

This page intentionally left blank. 
WHC-SD-WM-DQ0-007 Rev. 0

\section{APPENDIX A}

\section{DESCRIPTION OF DQO PROCESS}

The basic structure of the DQO process consists of seven steps. The steps are sequential, and each step is dependent on the previous step. The seven steps are:

- Step 1: State the problem

- Step 2: Identify the decision

- Step 3: Identify the inputs to the decision

- Step 4: Define the study boundaries

- Step 5: Develop a decision rule

- Step 6: Specify acceptable limits on decision errors

- Step 7: Optimize the design

\section{STEP 1: STATE THE PROBLEM}

The context of the problem is established by reviewing and summarizing existing information and describing the approach(es) under consideration to address the problem. During this step, the participants that should be involved in planning are identified and any practical constraints (limits of measurement technology, budgetary or time constraints) that might limit the approaches to problem resolution are recognized.

\section{STEP 2: IDENTIFY THE DECISION}

A statement of the decision(s) that must be resolved based on data, including the possible decision outcomes (alternative courses of action) are identified. In addition, secondary data uses are specified.

\section{STEP 3: IDENTIFY THE INPUTS TO THE DECISION}

The information needed to make the decision is specified and the measurements that must be made to generate this information specified. Measurements needed to support secondary data uses should also be specified during this step. Typically the planning team iterates back to this step after attempting to specify the decision rule. At that point further focusing of the inputs to the decision frequently occurs. Any variables that are not included in the decision rule come under closer scrutiny. If a convincing argument cannot be made for its inclusion, the variable is dropped from the list of required measurements.

\section{STEP 4: DEFINE THE STUDY BOUNDARIES}

The spatial area or volume to which a decision will apply and within which data should be collected are defined. The planning team should consider whether representative (random) sampling is required or practical, and should define what population the data may represent and the decisions the data can 
be applied to. The smallest sub-population of tank waste or tank atmosphere for which a separate decision might be made should be specified. For example, if a separate decision will be made for each layer of material in the tank, data representative of each layer must be collected. Finally, some phenomena are variable over time within the tanks. The time frame for which a decision will be made should be specified. Also, for some measurements the time period over which samples or measurements should be taken in support of decision making should be specified.

\section{STEP 5: DEVELOP A DECISION RULE}

The outputs from previous steps are integrated during this step into one or more statements that describe how data will be summarized and combined to form a result (mean, median, maximum, etc.) that will be used to determine the decision outcome. This step defines how the data generated from the study will be used. Typically the decision rule is stated as an "if... then..." statement that defines the conditions that would cause the decision maker to chose among alternative courses of action. The decision rule ignores the possibility of uncertainty in the data results (uncertainty is considered in Step 6).

\section{STEP 6: SPECIFY ACCEPTABLE LIMITS ON DECISION ERRORS}

The decision maker's (key data user's) acceptable decision error rates are defined in this step based on a careful consideration of the consequences of making incorrect decisions. By specifying decision error tolerances, the decision maker (data user) is accepting the fact that some probability of making an incorrect decision is inevitable because data can never perfectly reflect truth. The limits on decision errors drive many aspects of the design, including the number of samples and required precision and accuracy of the measurements. Iteration back to this step frequently occurs in order to balance the cost of collecting data against the uncertainty that can be accepted in the decision. It should be noted that although decision errors may be affected by analytical uncertainties, decision error tolerances are not the same as analytical error tolerances.

\section{STEP 7: OPTIMIZE THE DESIGN}

This step requires that the DQOs generated in the previous steps be carefully reviewed. The design team then translates the problem into a statistical framework, utilizes existing data and knowledge to specify the form of the underlying distribution and to estimate other key design parameters (e.g., the mean and variance of the underlying distribution and the cost of obtaining data), and generates alternative sampling designs. The most resourceefficient design that ensures an acceptable probability of making incorrect decisions is usually selected. If no design can be developed that meets all of the constraints specified (e.g., uncertainty limits and cost limits), then the planning team iterates back to earlier steps. Either a decision to relax or alter earlier DQO outputs is made, or a different approach may be selected (e.g., a decision may be made without data or with a different set of data). 
The DQO process is meant to be iterative in nature. If measurements or decision error tolerances are deemed to be unattainable as one progresses through the DQO steps, reevaluating requirements outlined in earlier steps may be necessary. For some applications, sufficient progress through the first few steps may have been accompl ished previously such that only documentation of the previous thought process cast in the context of the DQO logic may be needed before progressing through the remainder of the DQO steps. 
WHC-SD-WM-DQO-007 Rev. 0

This page intentionally left blank. 
WHC-SD-WM-DQO-007 Rev. 0

\section{APPENDIX B}

FORNULAS AND STATISTICAL ISSUES 


\section{WHC-SD-WM-DQO-007 Rev. 0}

This page intentionally left blank. 


\section{APPENDIX B}

FORNULAS AND STATISTICAL ISSUES

The underlying formulas and calculations that provided many of the results of this paper are provided in this appendix. This appendix will describe the formulas for the number of cores calculation, provide analys is of variance calculations for estimates of uncertainty, and provide an explanation of the non-central $t$-distribution that was used in calculating the achievable probabilities in Section 6.0.

\section{NUMBER OF CORES FORMULA}

The specifications that relate to the discomfort curves in Section 5.0 are the fundamental inputs to the calculations. The hypotheses allow the decision maker to state that if the difference between the decision threshold, $T_{0}$, and an alternate threshold, $T_{1}$, is greater than or equal to a specified value, then the power of the test $(1-\beta)$ must be greater than or equal to a specified level. The decision rule for ferrocyanide in a quarter segment specifies that $T_{0}=8 w t \%, T_{1}=4 w t \%, \alpha=0.20$, and $\beta=0.20$. For these specifications, the decision maker is stating that if the difference between 8 wt\% and $T_{1}$ is greater than or equal to 4 wt\%, then the power of the test must be greater than or equal to $80 \%$.

A general formula that applies to the one-sided tests is given by:

$$
n=\frac{\left(z_{1-\alpha}+z_{1-\beta}\right)^{2} R S D^{2}}{\left(\frac{T_{1}-T_{0}}{T_{0}}\right)^{2}}
$$

where $z_{1-\alpha}$ and $z_{1-\beta}$ are obtained from the standard $z$ table.

\section{ANALYSIS OF VARIANCE CALCULATIONS}

The RSD (relative standard deviation) in the above formula is the estimate of uncertainty that is addressed in Section 6.2 of this report. By definition, RSD is $\sigma / \mu$ where $\sigma$ is the estimate of uncertainty and $\mu$ is the mean of the distribution of the null hypothesis, $H_{0}$. The RSD accounts for the spatial and analytical uncertainties.

To obtain the RSD of $22 \%$ for the safe versus conditionally safe or unsafe decision rule, variance components were computed for total cyanide data. The variance components procedure resulted in estimates of spatial and analytical uncertainties for total cyanide. Data from DSC measurements, the measurements that will actually be used to determine ferrocyanide, were not available to estimate spatial uncertainties. The approach used to calculate total uncertainty was to use the spatial and analytical uncertainty from the DSC measurements, which was available from the labs, and the spatial uncertainty from the total cyanide measurements (the assumption is that the uncertainty 
would not be affected significantly by the method of measurement). This resulted in estimates of analytical uncertainty $=5 \% \mathrm{RSD}$, and estimates of core-to-core uncertainty (spatial) $=21 \%$. The RSDs are combined by multiplying each RSD by the estimated mean, squaring the standard deviations to get a variance, adding the variances, taking the square root, and dividing by the mean. The combined uncertainties resulted in a $22 \% \mathrm{RSD}$.

To obtain the RSD of $22 \%$ for the conditionally safe versus unsafe decision rule, similar techniques to the one described above were used. Moisture measurements were used to estimate analytical and spatial uncertainties for moisture. However, the moisture and ferrocyanide estimates of uncertainty needed to be combined to represent the decision rule. The variance for the equation $3 / 4$ (wt\% fuel - 8 wt\%) is equal to the variance for ferrocyanide plus $(3 / 4)^{2}$ times the variance for moisture. The square root of this variance divided by the combined mean resulted in an RSD of $22 \%$ for that decision rule.

\section{NON-CENTRAL $t$-DISTRIBUTION}

To calculate the achievable probabilities for decision error provided in Section 6.0, the assumption is made that the assumed uncertainties are the estimated uncertainties after two cores have been taken and the measurements in the laboratory have been completed. This assumption places the non-central $t$-distribution as the underlying distribution. The method of showing how the non-central $t$-distribution is applied is given below.

For each sample event, compute the mean ( $x-b a r)$, and the standard deviation(s) and construct:

$$
\bar{x}+t * s / \sqrt{n}
$$

Compare to $u_{0}$. Then,

$$
\operatorname{Pr}\left(\bar{x}+t * s / \sqrt{n} \leq \mu_{0}\right)=\operatorname{Pr}\left(\frac{\bar{x}-\mu_{0}}{s / \sqrt{n}} \leq-t\right)
$$

then, after algebraic manipulation

$$
\operatorname{PI}\left(\frac{\frac{\bar{x}-\mu}{\sigma / \sqrt{n}}+\frac{\mu-\mu_{0}}{\sigma / \sqrt{n}}}{\sqrt{\frac{\left(\frac{(n-1) s^{2}}{\sigma^{2}}\right)}{(n-1)}}} \leq-t\right) \text {, }
$$


WHC-SD-WM-DQ0-007 Rev. 0

which equals

$$
\operatorname{Pr}\left(\frac{N(0,1)+8}{\sqrt{\frac{\chi_{v}^{2}}{v}}} \leq-t\right) ;
$$

then, $\operatorname{Pr}\left(T_{\delta, v} \leq-t\right)$; where $T_{\delta, v}$ is Non-Central t-Distribution with $\nu$ degrees of freedom and non-centrality parameter $\delta$ is

$$
\delta=\frac{\mu-\mu_{0}}{\sigma / \sqrt{n}}
$$


WHC-SD-WM-DQO-007 Rev. 0

This page intentionally left blank. 
WHC-SD-WM-DQ0-007 Rev. 0

\section{APPENDIX C}

SENSITIVITY CALCULATIONS

C-1 
WHC-SD-WM-DQ0-007 Rev. 0

This page intentionally left blank. 


\section{SENSITIVITY CALCULATIONS}

As stated in Section 4.2 , the fuel decision rule is:

- If the fuel concentration average for all homogenized quarter segment sludge layers (half segment for saltcake) is less than or equal to $8 \mathrm{wt} \%$ as disodium nickel ferrocyanide $\left[\mathrm{Na}_{2} \mathrm{NiFe}(\mathrm{CN})_{6}\right]$ on an energy equivalent basis (i.e., $115 \mathrm{cal} / \mathrm{g}$ of dry material), then the tank is categorized as safe.

This translated into a statistical hypothesis test where the null hypothesis, $H_{0}$, and alternate hypothesis, $H_{1}$, were defined as:

$H_{0}$ : Fuel in quarter segment $(\mu)>8 \%$ wt\% (zero free water) as $\mathrm{Na}_{2} \mathrm{NiFe}(\mathrm{CN})_{6}$ (conditionally safe or unsafe)

$H_{1}$ : Fuel in quarter segment $(\mu) \leq 8 w t \%$ (safe)

There are two types of decision errors that should be controlled. The first (Type I) is made when one concludes that $H_{1}$ is true when $H_{0}$ is true. The second (Type II) is concluding $H_{0}$ is true when $H_{2}$ is true. The probability of making each type of error is dependent on several factors. The number of cores obtained, the true average concentration in a tank, the estimated underlying statistical distribution (variance and shape of distribution) and the statistical test performed, all affect the probability of making incorrect decisions. Therefore, the a priori estimates of probability of making incorrect decisions are only as good as the a priori assumptions on the statistical distribution and estimates of variability (spatial and analytical).

The key assumptions applied in calculating the probabilities of decision errors for the ferrocyanide decision rules are that the sample results are independent and normally distributed (be11-shaped curve), the fuel concentration spatial and analytical variations will be the same as those observed in ferrocyanide tanks $241-C-109$ and 241-C-112, and the samples obtained are representative. The spatial and analytical RSD was estimated to be $22 \%$ at $8 \mathrm{wt} \%$ fuel concentration.

A key parameter that must be established is the acceptable probability of making an incorrect decision when the true fuel concentration in a quarter segment is slightly greater than $8 \mathrm{wt} \%$. This was specified to be 0.20 (see Section 5.0). That is, if the true fuel concentration in a quarter segment is $8 \mathrm{wt} \%$, then it is acceptable to have up to a $20 \%$ chance of deciding that the fuel concentration is less than or equal to $8 \mathrm{wt} \%$ (categorizing the tank as safe).

\section{EFFECT OF INCREASING NUMBER OF CORE SAMPLES}

One way of reducing the risk of making an incorrect decision is to increase the number of core samples taken. In this section, the effect of increasing the number of cores on the achievable probabilities of making incorrect decisions is examined. 
The probability of concluding that the tank is either conditionally safe or unsafe was calculated varying the assumed true ferrocyanide concentration and the number of core samples. Figures $\mathrm{C}-1$ and $\mathrm{C}-2$ show these probabilities (in the form of power curves) given a fixed probability of making an error when at the 8 wt\% threshold of 0.20 and 0.05 respectively. As expected, when the Type I error at $8 \mathrm{wt} \%$ is tightened from $20 \%$ to $5 \%$, the probability of a Type II error increases significantly if the true ferrocyanide concentration is less than 6 wt\%.

Probabilities of making incorrect decisions are presented in Table C-l for several combinations of number of cores, true ferrocyanide concentrations, and fixed Type I error rate at 8 wt\%. For example, if two cores are obtained, the achievable probability, when the true ferrocyanide concentration is $4 \mathrm{wt} \%$, is $94 \%$. When the true concentration is $2 \mathrm{wt} \%$, there will be a $99.5 \%$ chance of making a correct decision, and when the true concentration is 1 wt\%, there will be a $99.9 \%$ chance of making the correct decision. If three core samples were obtained and the true ferrocyanide concentration is 12 wt\%, there will be a greater than $99.99 \%$ chance of making a correct decision.

In general, because the tanks are assumed conditionally safe or unsafe until proven otherwise, the probabilities of making a Type I decision error are very small. This probability is little affected by increasing the number of core samples for higher fuel concentrations, as illustrated in Figures $\mathrm{C}-1$ and $\mathrm{C}-2$. However, the probability of concluding that a tank is conditionally safe or unsafe when it is really safe (Type II decision errors) is affected by the number of cores taken, particularly if a Type I decision error $\leq 5 \%$ is required.

\section{LIMITING RSD}

In an effort to determine how large the RSD can be and still achieve the desired probabilities outlined in the discomfort curves, the limiting RSD was calculated for various core sampling scenarios. These limiting RSDs were determined assuming a normal distribution and a constant standard deviation equivalent to the RSD at $8 \mathrm{wt} \%$. These results are shown in Figure C-3. If only two core samples are obtained, an RSD up to 33\% RSD can be tolerated and still meet the desired probabilities of decision errors. Similarly, if three cores are obtained, an RSD of up to $46 \%$ can be tolerated.

An evaluation was also performed to determine how large an RSD could be tolerated and still assure that the decision error probabilities affecting safety were maintained. In this case, only the right-hand side of the discomfort curves were of concern and the left-hand side (the probability of concluding that a tank was conditionally safe or unsafe when it was truly safe) was not controlled. An RSD of up to $73 \%$ would ensure that decision errors affecting safety risks would be controlled to acceptable levels defined by the right-hand side of the discomfort curves. 


$$
\text { WHC-SD-WM-DQ0-007 Rev. } 0
$$

Figure C-1. Power Curve, 8 wt\% Fuel and Type I Error Fixed at 20\%.

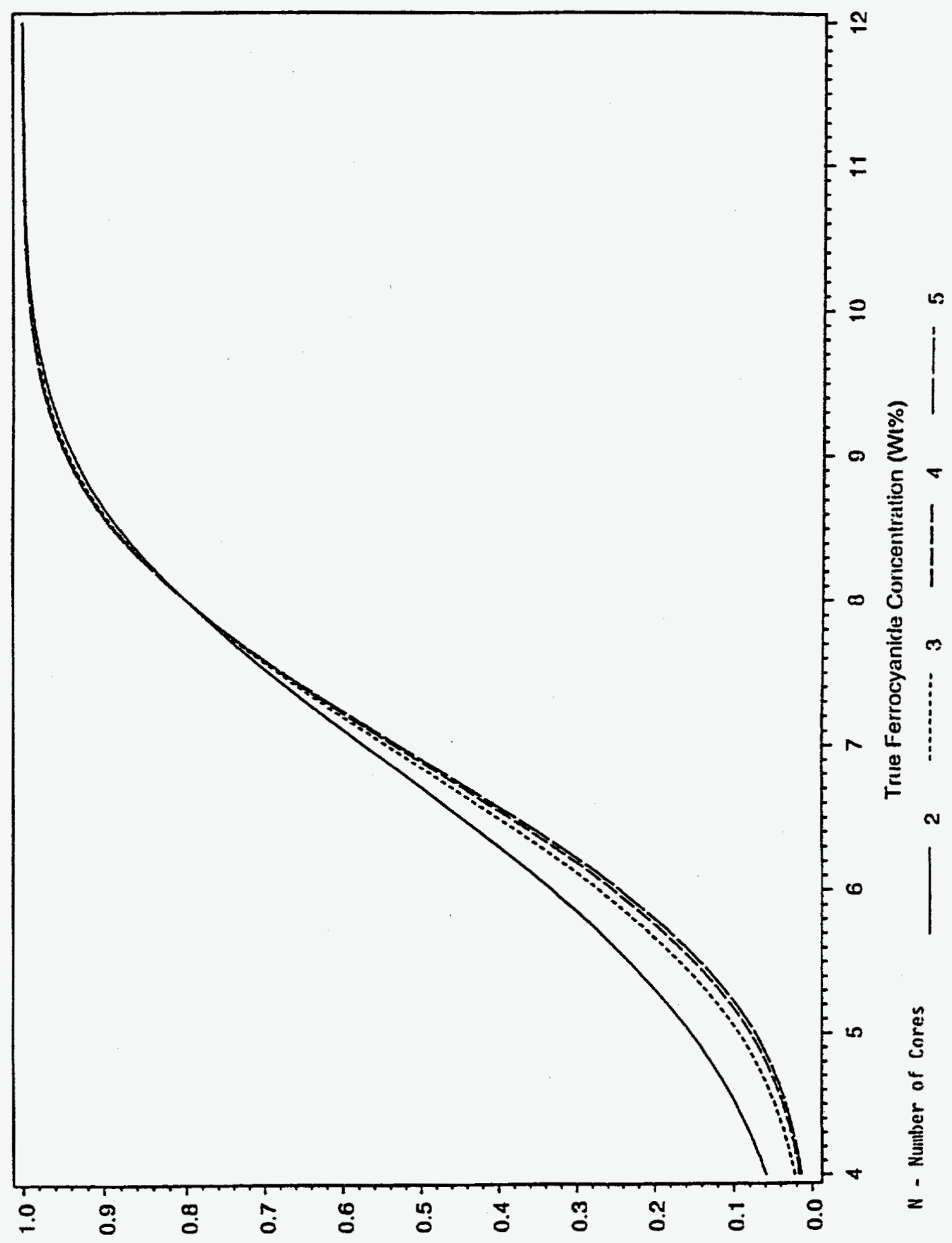

$$
\text { afRS KLleuo!z!puoj do afesun s! Xuel } 7847 \text { bu!pnlsuoj to } k 7 ! 1 \text { !qeqodd }
$$

C-5 
WHC-SD-WM-DQO-007 Rev. 0

Figure C-2. Power Curve, 8 wt\% Fue 7 and Type I Error Fixed at 5\%.

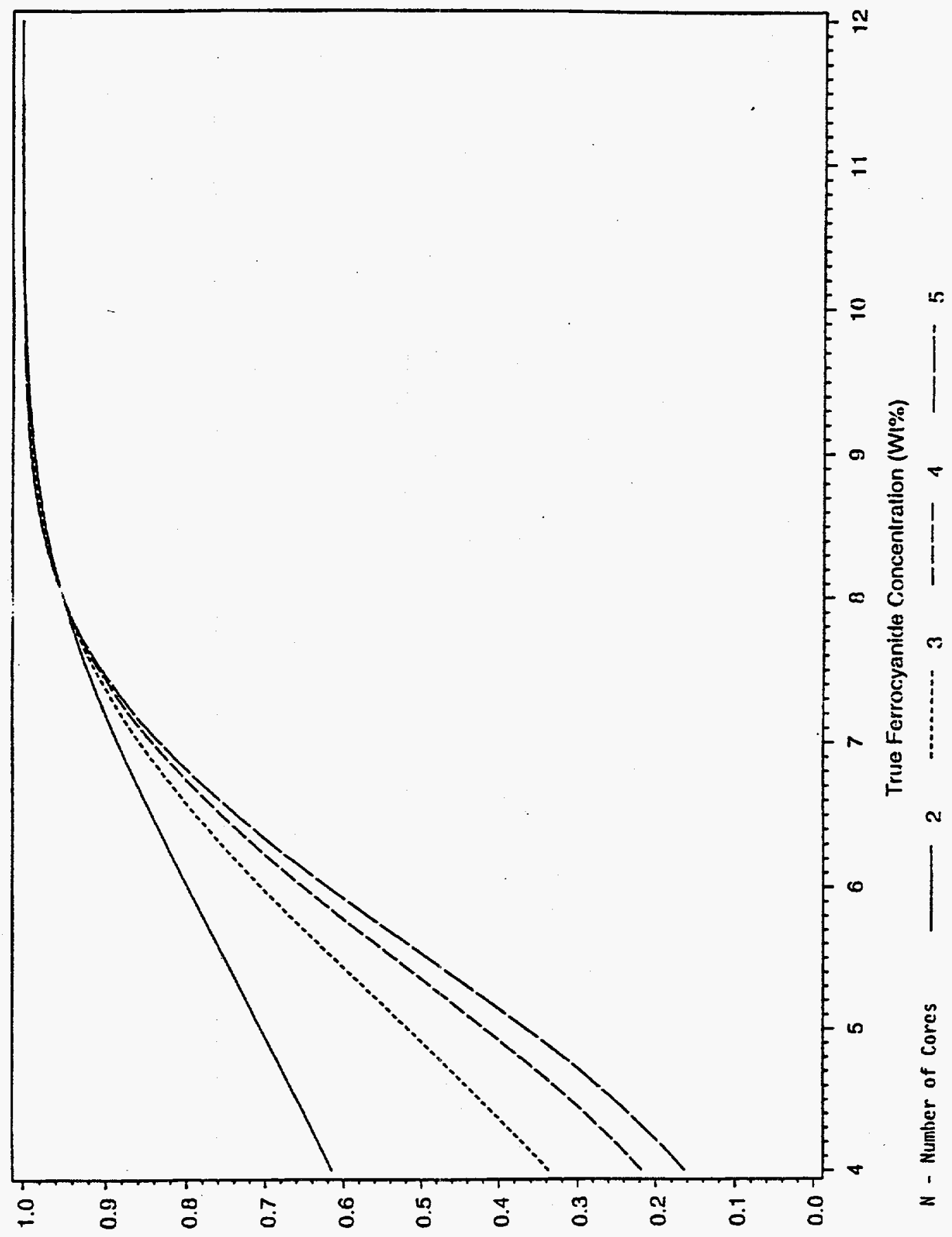

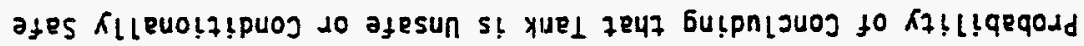


Table C-1. Probabilities of Making Incorrect Decisions, RSD $=22 \%$.

\begin{tabular}{|c|c|c|c|c|c|c|c|}
\hline \multirow{2}{*}{$\begin{array}{c}\text { Type 1 Error } \\
\text { at 8 Wt\% }\end{array}$} & \multirow{2}{*}{$\begin{array}{c}\text { True Conc. } \\
\text { (wt\%) }\end{array}$} & \multirow{2}{*}{$\begin{array}{c}\text { Type of } \\
\text { Error }\end{array}$} & \multirow{2}{*}{$\begin{array}{c}\text { Acceptable Error } \\
\text { Probabilities }\end{array}$} & \multicolumn{4}{|c|}{ Number of Cores } \\
\hline \hline $20 \%$ & 2 & II & Not specified & 0.00460 & 0.00001 & $<.00001$ & $<.00001$ \\
\hline $20 \%$ & 4 & II & $\leq 0.20$ & 0.05876 & 0.00422 & 0.00038 & 0.000036 \\
\hline $20 \%$ & 6 & II & Not specified & 0.33240 & 0.17757 & 0.10038 & 0.05771 \\
\hline $20 \%$ & 8 & I & $\leq 0.20$ & 0.20000 & 0.20000 & 0.20000 & 0.20000 \\
\hline $20 \%$ & 10 & I & Not specified & 0.01245 & 0.00388 & 0.00137 & 0.00052 \\
\hline $20 \%$ & 12 & I & $\leq 0.05$ & 0.00010 & $<.00001$ & $<.00001$ & $<.00001$ \\
\hline $20 \%$ & 15 & I & $\leq 0.01$ & $<.00001$ & $<.00001$ & $<.00001$ & $<.00001$ \\
\hline $5 \%$ & 2 & II & Not specified & 0.45073 & 0.03279 & 0.00065 & 0.00001 \\
\hline $5 \%$ & 4 & II & $\leq 0.20$ & 0.61508 & 0.20650 & 0.04404 & 0.00769 \\
\hline $5 \%$ & 6 & II & Not specified & 0.79862 & 0.62359 & 0.45910 & 0.32797 \\
\hline $5 \%$ & 8 & I & $\leq 0.20$ & 0.05000 & 0.05000 & 0.05000 & 0.05000 \\
\hline $5 \%$ & 10 & I & Not specified & 0.00288 & 0.00070 & 0.00019 & 0.00006 \\
\hline $5 \%$ & 12 & I & $\leq 0.05$ & 0.00002 & $<.00001$ & $<.00001$ & $<.00001$ \\
\hline $5 \%$ & 15 & I & $\leq 0.01$ & $<.00001$ & $<.00001$ & $<.00001$ & $<.00001$ \\
\hline
\end{tabular}


Figure C-3. Limiting RSD Achieving Desired Probabilities for Decision Errors

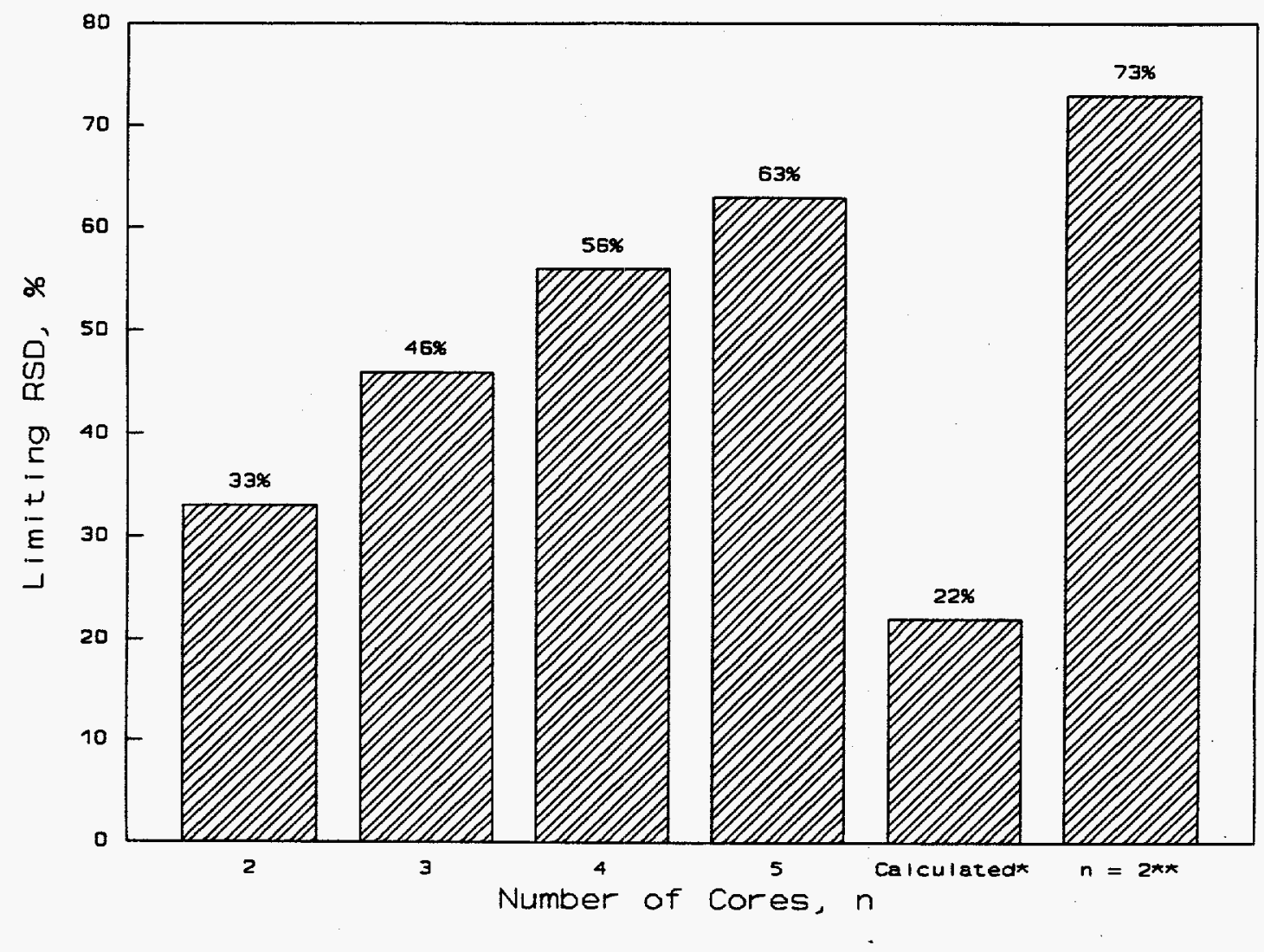

*Calculated from 241-C-109 and 241-C-112 data.

**protection from Type I errors only. 
WHC-SD-WM-DQ0-007 Rev. 0

APPENDIX D

INDEPENDENT REVIEW OF 22\% RSD CALCULATION 
WHC-SD-WM-DQO-007 Rev. 0

This page intentionally left blank. 


\section{OAK RIDGE NATIONAL LABORATORY POST OFFICE BOX 2008 \\ OAK RIDGE, TENNESSEE 37831-6367}

May 23, 1994

Mr. Brent Pulsipher

Statistics Design and Analysis Group

Mail Stop K734, P.O. Box 999

Richland, Washington 99352

Dear Brent,

I have reviewed your variance components analysis for ferrocyanide sampling. My comments and an alternate analysis are attached. My analysis differs a bit from yours, but we both come to the same basic conclusion: the DQO's seem to be met, even with just two observations per tank segment, and since t-tests cannot be performed with fewer than two observations, you cannot reduce the number of observations in each tank segment. It is conceivable that you might meet the DQO's with less than a tank segment census, but I have not pursued that idea. We agree on the basic model and computational method for extracting variance components.

I hope my comments and alternate analysis are satisfactory. Your work has been carefully done, and is clearly described in your report. Thanks for asking me to review it.

Sincerely,<smiles>C1CC[Ge]C1</smiles>

Richard L. Schmoyer, Statistics Group 


\section{Review of Ferrocyanide Sample-Size Determination Problem}

The purpose of this review is to address several concerns raised by the Defense Nuclear Facility Safety Board about a variance components analysis used in sample-size determination for ferrocyanide tank sampling. These concerns, as described by Cathy Anderson are, "was the model used to estimate the variance components adequate to represent the way the data was obtained," and "given the correct model, did the computer program used to compute the variance components do so appropriately, and were the correct options chosen through the 'canned' functions." Here I interpret "given the correct model" to mean "assuming that the correct model has been used." Cathy described my task in a Statement of Work as (1) to review and reanalyze the statistical model and software computations as originally completed, (2) to estimate the variance components using appropriate statistical tools, independent of the previous analysis, and (3) to summarize the findings in a letter.

Before giving details of my analysis let me summarize. The primary decision rules here are t-tests. My analysis differs a bit from yours, but we both come to the same basic conclusion: in spite of the wide critical values for the t-1 distribution, the DQO's seem to be met, even with just two observations per tank segment. Since t-tests cannot be performed with fewer than two observations, you cannot reduce the number of observations in each tank segment. It is conceivable that you might meet the DQO's with less than a tank segment census, but I did not pursue that idea.

Here are my analogs of your Tables 6-1 and 6-2 in your report "Data Requirements for the Ferrocyanide..." (WHC-EP-0728).

Table 1. Achievable Probabilities for the Safe vs Not-Safe Test

\begin{tabular}{cccc}
\hline Fuel (\%) & $\begin{array}{c}\text { EQstimate of } \\
\text { Probability }\end{array}$ & $\begin{array}{c}\text { 95\% Asymptotic } \\
\text { Achievable Probability } \\
\text { for Decision Error }\end{array}$ & $\begin{array}{c}\text { Upper Confidence Bound } \\
\text { for Achievable Probability }\end{array}$ \\
\hline 4 & .20 & $<.0001$ & .021 \\
8 & .20 & 0.20 & .200 \\
12 & .05 & 0.0008 & .024 \\
15 & .01 & $<.0001$ & .007 \\
\hline
\end{tabular}

Table 2. Achievable Probabilities for the Conditionally Safe vs Unsafe Test

\begin{tabular}{rcccc}
\hline Fuel (\%) & Water (\%) & $\begin{array}{c}\text { DQO } \\
\text { Probability }\end{array}$ & $\begin{array}{c}\text { Estimate of } \\
\text { Achievable Probability } \\
\text { for Decision Error }\end{array}$ & $\begin{array}{c}\text { 95\% Asymptotic } \\
\text { Upper Confidence Bound } \\
\text { for Achievable Probability }\end{array}$ \\
\hline 8 & 24 & .01 & $<.0001$ & $<.0001$ \\
15 & 24 & .05 & $<.0001$ & $<.0001$ \\
26 & 24 & .10 & 0.10 & 0.10 \\
26 & 20 & .05 & $<.0001$ & $<.0001$ \\
26 & 12 & .01 & $<.0001$ & $<.0001$ \\
\hline
\end{tabular}


The data used to compute these tables is the 36 observations from tanks c109 and c112, which Cathy sent me via email. In that data the units are "wgt\%*1000" for ferrocyanide and "wt\%TGA" for water. I divided the ferrocyanide data by 1000 and then treated the units for both ferrocyanide and water simply as weight percent.

It is obvious from Tables 1 and 2 that my analysis differs from the one in your report. I used the same basic model you did to estimate the core-to-core and lab (and other) error variances, but I used log(fuel) instead of fuel, and I did the power analyses slightly differently. I next discuss how I arrived at the model, the rationale for the $\log$ transform, and the power analyses.

For dependent variable $y$, the variance components model is

$$
y=\operatorname{segment}(\tan k)+\operatorname{core}(\tan k)+\operatorname{core}(\tan k \text {,segment })+\text { error. }
$$

To arrive at this model, I first noted that, ultimately, a t-test will be performed on data for each fixed tank and segment. An observation y will have a component of variance due to cores and an independent component due to lab error. The component of variance due to cores will reflect a main effect of cores, but not an interaction of cores with segments, because a separate $t$-test will be performed for each tank segment. Therefore, it is the main effect of cores (or equivalently cores within tanks) that will affect the t-test error; the interaction of cores with segments, which is accounted for by the core(tank,segment) term, will not affect the t-test error. As the segment(tank) component will not affect the test error either, we seek to estimate $\operatorname{Var}($ core(tank)) + Var(error).

As you did, I also fit the model (1) using the restricted maximum likelihood estimation (RMLE) option of the Varcomp procedure in SAS.

My safe-vs-not-safe test is about the same as yours, but I estimated the relative standard deviation, RSD $=[\operatorname{Var}(\operatorname{core}(\tan \mathrm{k}))+\operatorname{Var}(\mathrm{error})]^{1 / 2} / \mathrm{E}(\mathrm{y})$, differently. I think that the appropriate assumption here is that $\operatorname{Var}(y)$ is proportional to $E(y)^{2}$, that is, that the coefficient of variation, $C V=\operatorname{Var}(y)^{1 / 2} / E(y)$, is constant. This is reasonable, because, as the ferrocyanide concentration diminishes, its variability should also. $\operatorname{Var}(\log (y))$ is approximately $\operatorname{Var}(y) / E(y)^{2}$, which is

$$
\frac{\operatorname{Var}(\text { segment(tank)) }}{E(y)^{2}}+\frac{\operatorname{Var}(\operatorname{core}(\tan k))}{E(y)^{2}}+\frac{\operatorname{Var}(\operatorname{core}(\operatorname{tank}, \text { segment) }}{E(y)^{2}}+\frac{\operatorname{Var}(\text { error })}{E(y)^{2}} .
$$

Thus, we can use (1) with $\log (y)$ instead of $y$, and partition the variance of $\log (y)$ to obtain an estimate of $\left[\operatorname{Var}(\operatorname{core}(\operatorname{tank}))+\operatorname{Var}(\text { error) }]^{1 / 2}\right.$ under the $\log$ model, which is approximately the RSD. Call that estimate rsd.

Now [Var(core(tank)) $+\operatorname{Var}(\text { error) }]^{1 / 2}$ for the original untransformed y can be estimated using rsd $\times m n$, where $\mathrm{mn}$ is an estimate or assumed value for $E(y)$. In your analysis you estimated $\operatorname{Var}($ core(tank)) $+\operatorname{Var}($ error) using core-to-core and error variance components estimated with (1) but without a $\log$ transform. - essentially you allow one value of $\operatorname{Var}(y)$ and one value of $\operatorname{Var}(\operatorname{cor}(\operatorname{tank}))+\operatorname{Var}($ error) for all tank segments. In my constant-CV analysis, $\operatorname{Var}(\mathrm{y})$ and $\operatorname{Var}\left(\right.$ core(tank)) $+\operatorname{Var}\left(\right.$ error) are allowed to vary in proportion to $E(y)^{2}$. This might also have been accomplished with weights, but extracting variance components in a weighted analysis would be trickier than using logs. The constant-CV model suggests using a log transform for the whole analysis, so below, I also discuss using (1) under the assumption of lognormality.

Under (1) and RMLE, the core variance estimate is .0324 , and the emor variance estimate is .00075 , which gives an overall log-model core-plus-error variance estimate of .0331 . Thus, I got a fuel RSD estimate of $100(.0331)^{1 / 2}=18 \%$, as opposed to your $22 \%$. Using the asymptotic variance-covariance matrix calculated with Proc Varcomp and the formula

$$
\operatorname{Var}(\text { core }+ \text { error })=\operatorname{Var}(\text { core })+\operatorname{Var}(\text { error })+2 \operatorname{Cov}(\text { core }, \text { error }),
$$

where "core" and "error" here refer to log-model variance estimates, a sample variance for the log-model core-plus-error variance can be computed as $.0033+5.92 \times 10^{-8}+2\left(-2.99 \times 10^{-19}\right)$, which is .058. This can be used to compute an upper confidence bound for the log-model core-plus-error variance, and thus for the 
fuel RSD. The $95 \%$ upper confidence bound for the fuel RSD turns out to be $36 \%$.

More sophisticated variance components estimation techniques might be used to determine an upper confidence bound for the log-model core-plus-error variance, but as this is a sample-size determination with preliminary data and not a definitive inference with final data, using these asymptotic standard errors seems appropriate.

In your fuel power calculation, you assumed that $[\operatorname{Var}(\operatorname{core}(\operatorname{tank}))+\operatorname{Var}(\text { error })]^{1 / 2}=8 \times R S D$ for all levels of the fuel mean, $4,8,12$, and 15 . I use the relation $[\operatorname{Var}(\operatorname{core}(\operatorname{tank}))+\operatorname{Var}(e r r o r)]^{1 / 2}=$ mean $\times R S D$. Under my model, for the same RSD, at low values of: fuel, my tests are more powerful than yours under your model, but for mine, the Type 1 error rate diminishes more slowly with increasing fuel.

For the conditionally safe vs unsafe test, you assumed that the water and fuel concentrations are independent. I believe that is so for lab error, but, although the water concentration is roughly homogeneous, it does vary, and I am not convinced that it is independent of the fuel concentration. Therefore, instead of computing means for fuel and water, and using them as you did in the fuel-3/4water expression, I computed fuel- $3 / 4$ water for each core segment.

I also computed (fuel-8)/water for each core segment. As you know, this latter expression indicates a violation of conditional safety when it exceeds $3 / 4$. It seems to lead to a more powerful test than fuel$3 / 4$ water, at least for the fuel and water values in my Table 2 (and your Table 6-2). The error probabilities in Table 2 are for the statistic (fuel-8)/water.

A constant CV assumption is not reasonable for either fuel-3/4water or (fuel-8)/water, because the means of these statistics can be negative. For each, I performed the same variance components analysis that I did with fuel, but without taking logs - the same analysis you did for fuel and water. Again, by combining core-to-core and error variances, I estimated variances for both statistics. Again, using (2) and the RMLE asymptotic covariance matrix, I computed upper confidence bounds for the combined variances. The power calculation is also the same, except that I assumed constant $\operatorname{Var}(y)$, rather than constant $C V$.

The following table contains the results for the variance components analysis for fuel-3/4water and (fuel-8)/water.

Table 3. Variance Estimates \pm Standard Errors for Fuel-3/4Water and (Fuel-8)/Water

\begin{tabular}{llll}
\hline \multicolumn{1}{c}{ Variable } & \multicolumn{1}{c}{$\begin{array}{c}\text { Core-to-Core } \\
\text { Variance Estimate }\end{array}$} & \multicolumn{1}{c}{$\begin{array}{c}\text { Error } \\
\text { Variance Estimate }\end{array}$} & \multicolumn{1}{c}{ Sum } \\
\hline Fuel-3/4water & $61.4 \pm 962$ & $.68 \pm .13$ & $62.1 \pm 31.2$ \\
(Fuel-8)/water & $0.0032 \pm 2.5 \mathrm{E}-6$ & $0.000015 \pm 6.6 \mathrm{E}-11$ & $0.0032 \pm .0016$ \\
\hline
\end{tabular}

The standard errors for some of the variance estimates in Table 3 seem exorbitant relative to the estimates themselves. There is nevertheless sufficient precision in the laboratory procedure, and sufficiently little variability in the core-to-core differences that the upper bounds for achievable probabilities (Table 2) computed from them still seem $O K$.

Because there are only five cores, it does not seem worthwhile trying to test the normality of the coreto-core error term in (1). I used the following variation of the Shapiro-Wilk test as a check on the of normality of the lab (and other) error term in (1): In the variance components regression, let $Y$ be the vector of dependent variables $(y)$, let $r$ be the vector of regression residuals, and let $M$ be a matrix such that $r=M Y$. If the lab errors are iid $N\left(0, \sigma^{2}\right)$, then $r$ is multivariate normal with mean 0 and covariance matrix $\sigma^{2} M$. There exists an $n \times p$ orthogonal matrix $G$ such the $M=G^{\circ}$. (The columns of $G$ are the eigenvectors corresponding to the nonzero eigenvalues in an eigenvalue decomposition of $\mathrm{M}$.) If the lab errors are iid normal, then $G^{\prime} r$ is multivariate normal with mean 0 and variance $\sigma^{2} I$, where $I$ is the $p \times p$ identity matrix. So we can test normality of lab errors by testing the normality of the elements of G'r. I did the eigenvalue decomposition using SAS Proc IML and used the Shapiro-Wilk test in Proc Univariate to test normality. I 
got $p=.23$ for fuel- $-3 / 4$ water, and $p=.52$ for (fuel- 8 )/water.

A normality test for fuel is harder because of the log transform. I applied the above modified ShapiroWilk test to the log-model regression - as a test of lognormality - and got $p=.90$. I would certainly defer to your judgement about the statistical distribution of fuel, but you might also consider doing the analysis for fuel under the assumption of lognormality rather than normality, still assuming that (fuel-8)/water is normal.

Here is the analog of Table 1 for the lognormal model.

Table 4. Achievable Probabilities for the Safe vs Not-Safe Test - Lognormal Model

\begin{tabular}{cccc}
\hline Fuel (\%) & $\begin{array}{c}\text { DQO } \\
\text { Probability }\end{array}$ & $\begin{array}{c}\text { Estimate of } \\
\text { Achievable Probability } \\
\text { for Decision Error }\end{array}$ & $\begin{array}{c}\text { 95\% Asymptotic } \\
\text { Upper Confidence Bound } \\
\text { for Achievable Probability }\end{array}$ \\
\hline 4 & .20 & 0.0015 & .110 \\
8 & .20 & 0.20 & .20 \\
12 & .05 & 0.0001 & .013 \\
15 & .01 & $<.0001$ & .001 \\
\hline
\end{tabular}

As you can see, the DQO's are also met under the lognormal assumption.

Of course a lot is riding on the assumption of normality here, because a t-test with one degree of freedom is eminently nonasymptotic. Not that I see much in the way of alternatives to the usual lognormal or normal approaches in this setting of tiny sample sizes. My analyses, like yours, also assume that sampling approximates simple random sampling.

In conclusion, I would do both the safe-vs-not-safe and conditional tests a little differently, but I think that your sampling plan is correct. Obviously, you can look at the data many different ways after you get it. We agree on the basic model for extracting variance components. Except for minor variations, our analyses are the same. 
WHC-SD-WM-DQO-007 Rev. 0

This page intentionally left blank. 
Number of copies

\section{OFFSITE}

6

1

\section{ONSITE}

Science Applications International Corporation 20300 Century B1vd, Suite 200-B
1

3

4

U.S. Department of Enerqy, Richland Operations Office

R. F. Christensen (2)

R. E. Gerton (2)

Germantown, MD 20874

Ray S. Daniels (3)

U.S. Department of Energy

Germantown, MD 20874

James V. Antizzo

Charles 0'Dell (4)

John C. Tseng

Los Alamos National Laboratory

P.0. Box 1663

Los Alamos, NM 87545

Steve F. Agnew

Sandia National Laboratories

P.0. Box 5800

Albuquerque, NM 87185

Dana A. Powers, MS-0744

13

Westinghouse Hanford Company
EM-36, Trevion II

H. Babad

S7-30

K. E. Bell

T6-06

J. L. Deichman

H4-19

D. J. McCain

57-30

A. D. Rice

T6-06

R. D. Schreiber

Document Processing and Distribution (2)

EDMC

Information Release Administration (3)

R2-12

L8-15

H6-08

R1-05

TFIC

R1-20 